\title{
Essai de reconstitution des agrosystèmes et des ressources alimentaires dans les monts Mandara (Cameroun) des premiers siècles de notre ère aux années 1930
}

An attempt to reconstruct former agrosystems and food ressources in the Mandara Mountains from the First centuries CE until the 1930's

\section{Christian Seignobos}

\section{OpenEdition Journals}

\section{Édition électronique}

URL : http://journals.openedition.org/ethnoecologie/1836

DOI : 10.4000/ethnoecologie.1836

ISSN : 2267-2419

\section{Éditeur}

Laboratoire Eco-anthropologie et Ethnobiologie

\section{Référence électronique}

Christian Seignobos, «Essai de reconstitution des agrosystèmes et des ressources alimentaires dans les monts Mandara (Cameroun) des premiers siècles de notre ère aux années 1930 », Revue d'ethnoécologie [En ligne], 5 | 2014, mis en ligne le 30 juin 2014, consulté le 19 avril 2019. URL : http:// journals.openedition.org/ethnoecologie/1836 ; DOI : 10.4000/ethnoecologie.1836

Ce document a été généré automatiquement le 19 avril 2019

\section{cc)}

Revue d'ethnoécologie est mis à disposition selon les termes de la licence Creative Commons Attribution - Pas d'Utilisation Commerciale - Pas de Modification 4.0 International. 
Essai de reconstitution des agrosystèmes et des ressources alimentaires dans les monts Mandara (Cameroun) des premiers siècles de notre ère aux années 1930

An attempt to reconstruct former agrosystems and food ressources in the Mandara Mountains from the First centuries CE until the 1930's

\section{Christian Seignobos}

\section{NOTE DE L'AUTEUR}

La plupart des dessins ont été extraits de carnets de terrain ou réalisés à partir d'eux avec parfois l'appui de documents photographiques.

1 Fortement compartimentée en petits massifs de granit ruiniformes enserrant une suite de plateaux intérieurs la chaîne des Mandara culmine au monts Oupay à $1492 \mathrm{~m}$. La pluviométrie de 900 à $1100 \mathrm{~mm}$ chute en plaine, à Maroua, à $750 \mathrm{~mm}$, avant l'épisode de sécheresse de 1972-1973 et sa réplique en 1983-1984 (Figure 1). 


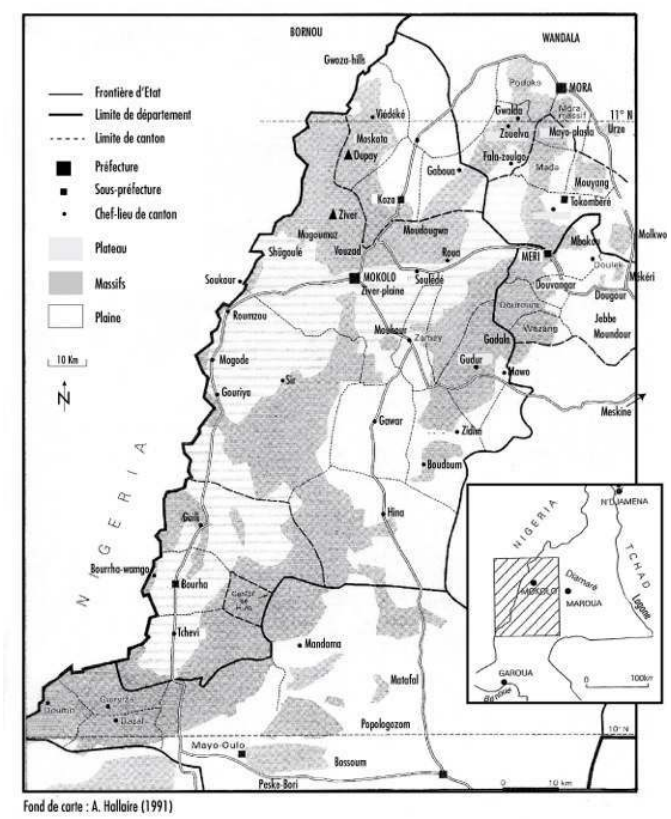

LES MONTS MANDARA - Corte des Toponymes cités

2 Les rochers sont partout, armant les profils des crêtes, dévalant en chaos de blocs cyclopéens, autour de vastes affleurements de la même roche mère granitique. Ici la classique dialectique homme/nature devient homme/rochers. L'habitat dans les Mandara (Figure 2), totalement dispersé ou parfois semi-groupé, se niche dans ces rochers qui font intrinsèquement partie de l'exploitation familiale. Les amoncellements granitiques sommitaux travaillés par l'érosion mécanique, favorisée de surcroît par l'action anthropique qui y entretient certains gros ligneux, libèrent quartz, micas, feldspath et divers éléments fins qui descendent progressivement avec le ruissellement. L'homme réussit à recycler à son profit la désagrégation en place des granits pour alimenter l'arène de ses terrasses et créer le plus de champs possible. Ces sols à jamais peu évolués, mis au bas de l'échelle des pédogenèses n'en supportent pas moins les plus fortes densités de peuplement de tout le bassin du lac Tchad. 


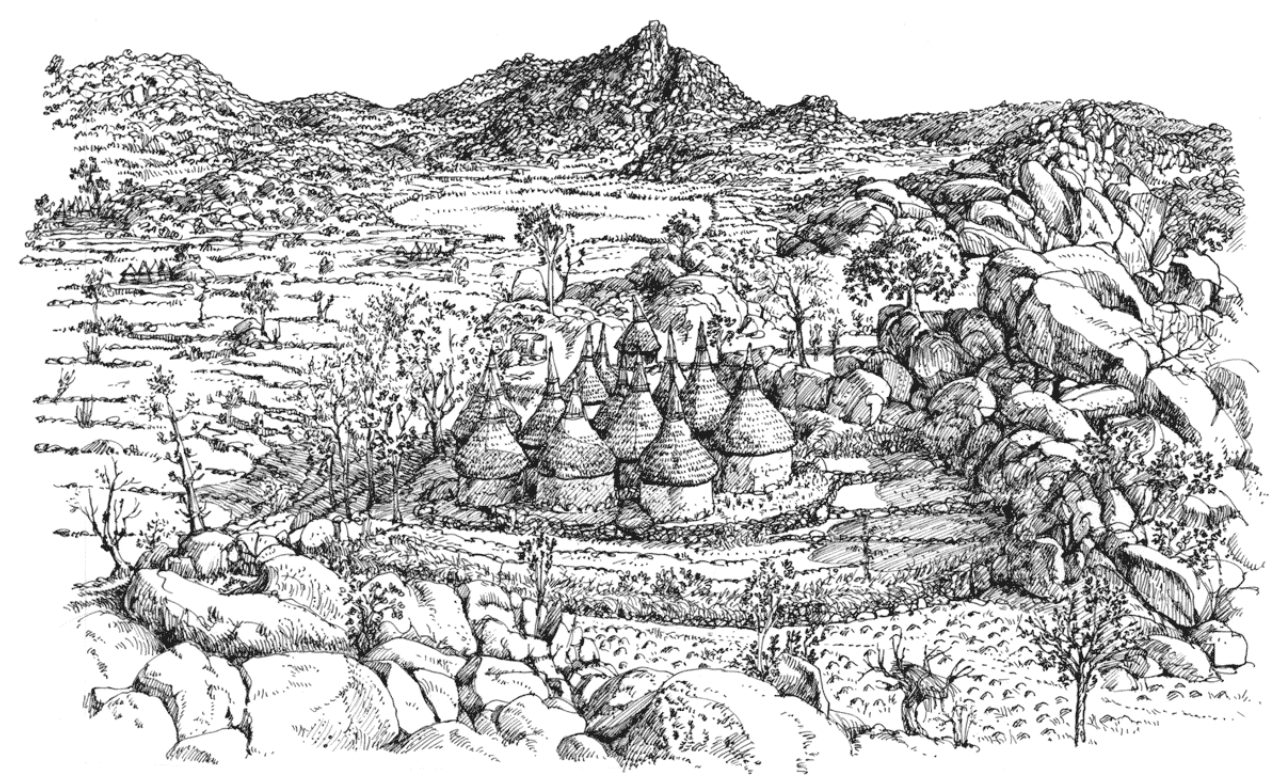

3 Le champ de case ${ }^{1}$ capte toute l'attention du montagnard. En dépit du fouillis végétal pendant la saison des pluies, il se révèle fortement structuré. Dans ce complantage généralisé s'individualisent des jardins de tabac, de maïs, de gombo... Grâce à cette vicinalité les terrasses du champ de case demeurent les mieux fumées et les mieux surveillées de toute l'exploitation. Cet espace joue un rôle essentiel dans l'acclimatation de nouveaux cultivars. Dans le passé toutes les nouvelles cultures y ont suivi une phase d'adaptation plus ou moins longue avant d'être conduites en champs sur de vastes surfaces. Le champ de case enregistre non seulement des départs mais aussi des retours. Cet espace près de l'habitation récupère des cultivars délaissés, désormais plus au service des rituels et de la pharmacopée.

Du peuplement ancien et complexe des monts Mandara nous ne retiendrons que quelques traits. On reconnaît un courant de peuplement qui s'est individualisé le long des Mandara occidentaux, issu pour l'essentiel du Bornou jusqu'à la Bénoué via le pays gude. Les flux de populations les plus continus durant un quasi millénaire et chargés d'apports culturels viennent du nord et nord-est. De petits groupes originaires des plaines du Tchad abordent la chaîne en s'accrochant aux pointements rocheux, sortes d'archipels qui la précèdent (Jebbé, Mékéri, Mbokou, Molkwo...). De là ils négocieront leur entrée sur la montagne. Une majorité d'entre eux glissent sur le flanc oriental, vers le sud, ou empruntent le fil conducteur de la convergence des mayos Tsanaga et Boula pour entrer par la première grande échancrure des Mandara, celle de Mowo-Goudour. Cette région fonctionne comme une vaste plaque tournante de peuplement.

5 Les populations empruntent ensuite les plateaux intérieurs, au nord comme au sud, pour intégrer plus facilement les massifs sur leurs arrières. Le gros du peuplement $\left(\mathrm{xI}^{\mathrm{e}} / \mathrm{XVI}^{\mathrm{e}}\right.$ siècle) occupe les Mandara centraux au sud de Goudour ${ }^{2}$. Enkystées dans des reliefs chaotiques peu élevés ces communautés ont pu vivre relativement préservées alors que celles des Mandara septentrionaux, dans des milieux plus âpres, continuent à recevoir de 
constants apports de la plaine qui les transformeront plus rapidement. Les groupes méridionaux se montreront plus conservateurs à la fois dans leurs encadrements politiques, leurs structures sociales et, bien évidemment, leurs systèmes agraires avec des cultivars ailleurs abandonnés et des élevages relictuels. Ils feront souvent fonction de référents pour des situations passées dans l'ensemble des Mandara.

Les mémoires collectives spontanées font sur le sujet des plantes du passé rapidement défaut. Les aliments du passé n'intègrent généralement pas les registres des traditionnalistes. On peut néanmoins collecter des bribes d'informations dans les récits étiologiques ou dans ceux concernant les ethnogenèses, les chartes de cohabitation et autres figures de mythes. Aussi pour retrouver des composantes alimentaires rattachées à des systèmes agraires du passé convient-il de privilégier d'autres indices.

On part d'un état des lieux des années 1930, avant les premiers "déperchements » administratifs contraints des populations des massifs de bordure. On en retrouve tous les traits, parfaitement conservés en montagne, lors de nos enquêtes qui s'échelonnent de 1970 à 2010. Tout commence avec l'inventaire des cultures relictuelles encore présentes. Leur recueil demeure un préalable et une base dans le questionnement du passé. Il fait ressortir des aires de fortes résiliences de systèmes agraires anciens qui serviront de référents pour d'autres régions à d'autres périodes. La nature des companagium (sauces) actuels renseigne sur des traits culinaires du passé maintenus dans des zones reculées, forcément recueillis auprès de vieux informateurs. Si les " aliments de base ${ }^{3}$ : éleusine, petit mil, sorgho et leurs combinaisons de farines s'appréhendent facilement, les sauces elles renvoient à des patrimoines culinaires autrement complexes.

Un registre semble incontournable, celui des cuisines rituelles, qui s'adressent aux mânes des ancêtres. Ce sont justement là "leurs repas", censément ceux de leur époque, accompagnés de libations de bière produites avec des céréales précises. Elles remplissent un rôle de médiation entre le monde des morts et celui des vivants. Il existe toutefois plusieurs niveaux d'ancêtres, ceux de la liste récitée devant le grenier-tabernacle de la concession de l'ainé et ceux des générations d'ancêtres supérieurs dont les cultes en appellent à d'autres nutriments issus de cultures plus anciennes. La nourriture donnée aux initiés et classes d'âges vise aussi une médiation avec les ancêtres et use d'ingrédients sacrificiels spécifiques.

9 La lecture des paysages et des parcs arborés anthropiques fournit également un bon outil dans la remontée du temps. Les arbres sélectionnés ou suscités sur les champs en terrasse fournissent le complément de ce qui se cultive. Ces formations végétales gardent comme sous scellés des essences relevant de productions devenues obsolètes.

10 L'absence, dans le passé, de grandes espèces cosmopolites africaines comme certains légumes, l'arachide, la canne à sucre... qui dans le bassin tchadien ont souvent connu des diffusions tardives, permet de s'interroger sur des productions antérieures et de rechercher ces ingrédients essentiels. Parmi eux, la réponse à une demande de graisse domine. Elle touche à la «félicité gastronomique » qui s'affiche toujours ruisselante de graisse. C'est le plat de fête et on ne se lave plus les mains pendant des jours afin d'en humer et d'en faire humer le fumet. Le besoin de mucilage relève d'abord d'une recherche organoleptique de la sauce, rendue indispensable par la nature même de la préparation d'éleusine, de petit mil ou de sorgho. Cette sauce doit prendre une consistance suffisamment glutineuse pour coller au morceau de pâte et pouvoir être ingérée par un simple glissement facilitant ultérieurement le transit intestinal. On recherche donc des légumes dits «liants» comme des feuilles fraîches ou séchées et 
réduites en poudre pour une meilleure conservation. Une longue cuisson de cette sauce agrémentée de sel de potasse l'épaissira encore.

11 Les administrateurs coloniaux ont souvent décrit les montagnards manifestant une constante "faim de sel ». Il servait même "d'appât » pour un chef de subdivision qui voulait rassembler un village pour un recensement (Lembezat $1961: 26$ ). Ils semblaient de fait mus davantage par une constante recherche permanente de sels nouveaux dans un besoin de stimulation gustative pour un évident plaisir sensoriel.

Il convient de réimaginer des époques où les légumes relevaient pour l'essentiel des seules brèdes. Les feuilles, le haako des Peuls est à la fois légume et sauce et l'on retrouve la même extension métonymique de sens dans bien d'autres langues. Cela engageait des formes de cueillette de proximité débouchant sur de pseudo-domestications. On liste alors un grand nombre d'arbres dont on a oublié qu'ils fournissaient une ressource en légumes-feuilles à l'état jeune: Tamarindus indica, Parkia biglobosa, Vitex doniana, nombre de Ficus et jusqu'au Faidherbia albida.

13 La littérature scientifique fait généralement du bassin du lac Tchad lato sensu une zone de domestication du pois de terre et de convergence des niébés. Le berceau afro-central se voit aussi crédité d'héberger le «foyer primaire » des "Coleus » spp. Le mil pénicillaire ayant été domestiqué dans le sahel sub-saharien, la région du lac Tchad se présenterait comme un espace de diversification secondaire. On l'applique également aux sorghos, toujours au seul présupposé d'un circum tchadien carrefour de flux migratoires et d'échanges caravaniers. L'abondance réelle de cultivars de sorghos correspond néanmoins à une véritable dialectalisation y compris dans les monts Mandara, sans doute redevable à des communautés émiettées, chacune ayant eu à cœur de façonner "ses " sorghos. Au vu des panels de sorghos, de leur importance dans la structuration des sociétés, de leur prégnance dans le religieux, de leur situation centrale dans l'habitation où tout vise à protéger les silos à grains et du raffinement de leur structure, on se trouve bien en présence d'authentiques céréaliculteurs. Plante «surculturelle», le sorgho est associé au pouvoir masculin intégrant discours intégrant tout l'héritage des ancêtres et les rituels afférents. En montagne "le sorgho est vivant», il peut «fuir » du champ comme il peut « augmenter » dans le grenier. Sa protection relèverait d'une « religion du $\mathrm{mil}^{4}{ }^{4}$, en l'occurrence du sorgho. Dès lors on ne peut concevoir que ces céréalicultures ne soient pas millénaires et pourtant...

14 Tout porte à croire que si le sorgho a été connu depuis longtemps, il a pu rester marginal dans maints systèmes agraires du passé. Écartés pour d'autres cultures, céréales ou tubercules, jugées plus fondamentales, gustativement plus prisées, prétendument plus nourricières ou moins vulnérables au climat et aux ravageur, les sorghos ont pu, comme le maïs apparu bien ultérieurement et appelé « petit mil d'Égypte » ou "petit mil de la maison ", se voir indéfiniment cantonnés à une culture d'appoint derrière les habitations. Les cultures en champ étaient alors réservées aux éleusines et aux mils pénicillaires. Ces céréales n'en avaient pas moins ouvert la voie aux sorghos.

15 Cet essai sur le manger et le boire dans les monts Mandara retrace l'évolution des agrosystèmes, qui se présente en trois tableaux, du plus récent au plus ancien, figée par les besoins de l'exposé bien qu'elle soit dynamique et pleine de chevauchements.

16 Le premier renvoie au point d'observation de départ, " 1930 », avant les descentes administratives forcées des montagnards en plaine. Cet état des lieux s'observe encore parfaitement trente à quarante ans après. Il s'agit d'agrosystèmes céréaliers avec pour la 
plupart une rotation biennale des cultures ou des restes de cette alternance sorgho/petit mil, légumineuses.

Le deuxième tableau met en jeu la rotation suivante : petit mil/éleusine et légumineuses, avec l'intrusion de plus en plus prégnante des sorghos dans le système agraire.

Le troisième tableau repose sur l'hypothèse d'agrosystèmes davantage fondés sur des tubercules accompagnés par des céréales à petits grains et toujours les mêmes légumineuses.

Dans l'analyse, l'agrosystème se réduit à deux pôles: le champ de case, espace d'acclimatation des nouvelles cultures et de récupération de celles devenues relictuelles, et les champs ouverts, généralement sur terrasses. Elle prend en compte pour chacun le panel de cultures et leur participation à la combinaison agraire, appuyé par une étude du parc arboré. La partie culinaire sélectionne comme entrées l'aliment du quotidien, la boule $^{5}$, le companagium, en l'occurrence les sauces et leurs différents composants: légumes et brèdes essentiels, mucilages, trompe-goût, matières grasses ou sucrées et, enfin, les boissons.

Tous les faisceaux d'hypothèses qui font sens reposent sur des degrés d'ancienneté ou d'antériorité des cultures et des modes culinaires sans pouvoir jamais s'appuyer sur des référents chronologiquement irréfutables. Les cadres temporels font défaut ou, à peine entraperçus, ils restent sujets à caution. Quel pas de temps attribuer au premier tableau, $\mathrm{du} \mathrm{XX}^{\mathrm{e}}$ au XVI ${ }^{\mathrm{e}}$ siècle? au deuxième, du XVI ${ }^{\mathrm{e}}$ au $\mathrm{x}^{\mathrm{e}}$ siècle ? et réserver enfin les époques antérieures au $\mathrm{x}^{\mathrm{e}}$ siècle au troisième tableau? Le curseur temps se montre susceptible d'importants changements d'amplitude dans le passé.

21 Même si nous évoquons l'introduction de certains cultivars, ce que nous prenons en compte de fait est leur mise en cohérence dans un système agraire, et cela peut se réaliser de façon très tardive par rapport à leur apparition.

Les résultats de nouvelles recherches, notamment archéologiques, permettront de valider ou non ce que nous présentons comme une évolution plausible des systèmes agraires montagnards et des formes d'alimentation qu'ils ont introduites au cours des siècles.

Nous exposerons l'état de trois agrosystèmes (ou agro-éco-socio systèmes) des monts Mandara référents qui serviront de cadres pour comprendre les traits alimentaires du quotidien, du saisonnier et du festif des populations.

24 Nous commençons par celui ou ceux de la décennie 1930. Ils ont été longtemps désignés dans la configuration développementiste comme climaciques, compris dans le sens de difficiles à bonifier.

\section{Un système céréalier de référence autour de la décennie 1930 (XVIII ${ }^{\mathrm{e}} \mathrm{XX} \mathrm{X}^{\mathrm{e}}$ siècle)}

\section{Des combinaisons agraires au service des sorghos}

Il n'existe pas pour les monts Mandara un agrosystème unique, mais plusieurs : un sans rotation et d'autres qui intègrent à des degrés divers des formes de rotations biennales (Figure 3). 
Figure 3 : Les monts Mandara septentrionaux (pays mofu)

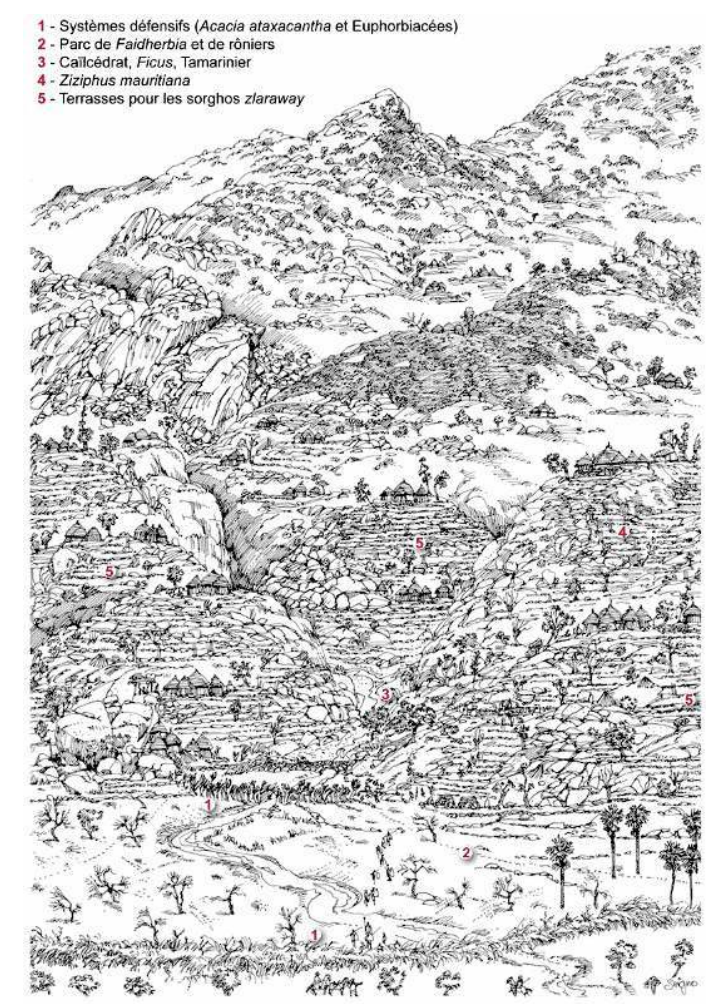

Le premier qui intéresse les massifs bordiers allant des Hina jusqu'à l'extrémité nord, aux Podokwo, signe une céréaliculture dominée par des sorghos de montagne à cycle long ( zlaraway en mofu) secondés par des sorghos rouges (salaway en mofu) à cycles précoces avec encore la présence de petits mils auxquels s'ajoute un cortège de cultures secondaires : niébés, oseille de Guinée, cucurbitacées, sésame...

$\mathrm{Au}$ contraire de l'idée reçue quant aux rotations biennales et pour la plus notoire, celle des Mafa qui alléguerait une réponse a posteriori à l'enclavement de massifs privés d'accès à la plaine et parmi les plus peuplés $\left(100\right.$ à $\left.150 \mathrm{hab} / \mathrm{km}^{2}\right)$, il s'agirait là d'un système relique, jadis plus largement répandu. On retrouve ces rotations appelées «l'année de l'homme » et "l'année de la femme " dans les Mandara méridionaux au service de densités de peuplement très mesurées $\left(20 \mathrm{hab} / \mathrm{km}^{2}\right)$. A. Hallaire a la première $(1988,1991)$ décelé de vieux clivages et des regroupements civilisationnels à travers tous les systèmes agronomiques (dont les rotations biennales) et certains aménagements clefs des terroirs comme les terrasses considérées plus, de son point de vue, comme des « faits de civilisations ». Cette approche ne va pas à l'encontre d'une réponse à une exploitation plus intensive du milieu et ne s'oppose en rien aux arguments fonctionnalistes de maintien de la fertilité des sols et à la lutte contre les ravageurs.

Les Mafa ont pratiqué jusque dans les décennies 1990-2000 une rotation avec l'année paire du calendrier grégorien, celle des hommes (sorgho zlaraway + éleusine) et l'année impaire, celle des femmes, (petit mil, niébé, oseille de Guinée, souchet) et hors rotation : pois de terre, taro, légumes divers.

29 Le rythme biennal reste fonctionnel chez les Daba et les Gude dans les Mandara méridionaux : le temps des hommes (sorghos à cycle long) et celui des femmes (dominé par les niébés). Chez les Daba Teleki, la sole des champs de brousse est occupée la 
première année - celle des femmes - par des niébés et une cucurbitacée oléifère ; la seconde année on cultive des zlaraway appelés ici emberaw et des éleusines tardives ; puis on pratique une jachère au bout de quatre ans. Le champ de case demeure également très structuré avec un jardin de tabac, un autre de maïs, de gombo et de courge, d'éleusines hâtives et de sorghos rouges également hâtifs. Il se prolonge par une bande auréolaire extérieure portant une rotation sorgho rouge + éleusine/légumineuse + culture d'une courge oléifère que l'arachide intègre plus tard, vers 1950.

Pour les Bana, Jimi, Njegn et Fali, la discipline de la rotation biennale a connu un relâchement, mais le rythme demeure avec une année où les cultures dites des femmes sont poussées : niébés, voandzou, souchet et cucurbitacée oléifère. On peut néanmoins parfaitement reconstituer la rotation binaire. Le temps des hommes, toujours l'année paire, recouvre celle des sorghos alors que le temps des femmes reste voué aux niébés et aux cucurbitacées oléifères.

31 Ces rotations impliquent que l'année des sorghos soit celle d'une production excédentaire, rendant compte ainsi de l'importance dans les Mandara des modes de conservation des récoltes ${ }^{6}$. L'année du petit mil et des cultures de femmes se présente, en revanche, comme une année de semi-disette. Pourtant cette année prépare l'année du sorgho par l'addition des cultures de légumineuses (niébés/pois de terre) et par des cultures céréalières peu exigeantes pour les sols : éleusines et petits mils. Cette rotation permettrait d'enrayer certaines maladies du sorgho comme les rouilles. Mais la réelle alternance opère entre sorghos et légumineuses. Vue sous l'angle des légumineuses, leur culture selon des cycles bisannuels témoigne d'un assolement particulièrement pertinent. Le niébé fixe dans le sol une quantité appréciable d'azote disponible en début de cycle pour la culture suivante, celle du sorgho, céréale exigeante. Le niébé s'avère en revanche sensible à une foule d'insectes phytophages, aussi une année sans permet-elle de casser le cycle de ces déprédateurs, bloquant ainsi toute pullulation potentielle. Mais il convient, pour qu'elle soit efficace, d'appliquer cette discipline sur une aire très vaste, aussi constate-t-on une rotation biennale entreprise en même temps sur le plus grand nombre de massifs ${ }^{7}$ (Pasquet \&Fotso 1991 : 337).

On observe une forte répercussion de cette rotation sur la vie sociale et religieuse. Le zlaraway reste la plante pivot autour de laquelle gravitent les rites agraires (Hallaire 1991: 190). Chez les Mafa, la fête du maray (taureau sacrifié) se déroule l'année du sorgho. Sur cette "année de l'homme» se calent d'autres disciplines agraires: taille des arbres, locations de terre... Cette rotation biennale s'identifie par ailleurs à un rythme social homme/femme, garant de stabilité, les temps cycliques amortissent les accidents de l'histoire. Il s'agit, là aussi, de l'alternance de deux régimes alimentaires, une année plus riche en sorgho et en graisse et l'autre fondée sur des céréales secondaires, mais surtout sur les niébés, les unes et les autres lissées, il est vrai, par un cortège de productions constantes (oseille de Guinée, gombo, pois de terre...).

On relève un ensemble très particulier de cultures hors rotations inféodées à certains biotopes humides du terroir dans des situations souvent opportunistes visant à récupérer l'eau qui sourd des pentes et auxquelles on assigne un rôle anti-érosif. Dans les Mandara, la lutte anti-érosive est toujours contingente de l'agrosystème. Les tarodières (Figure 4), aménagées parfois de façon pérenne, accompagnées de petites rizières en alvéoles contiguës, récupèrent l'eau des terrasses qui passe ensuite par les canaux en baïonnette des réseaux de billons plats dévolus au souchet. Les lourds billons de patates douces, dès 
leur introduction, très tardive, autour de 1960 dans la région de Mokolo, prolongeront encore ce dispositif.

\section{Figure 4 : Tarodières}

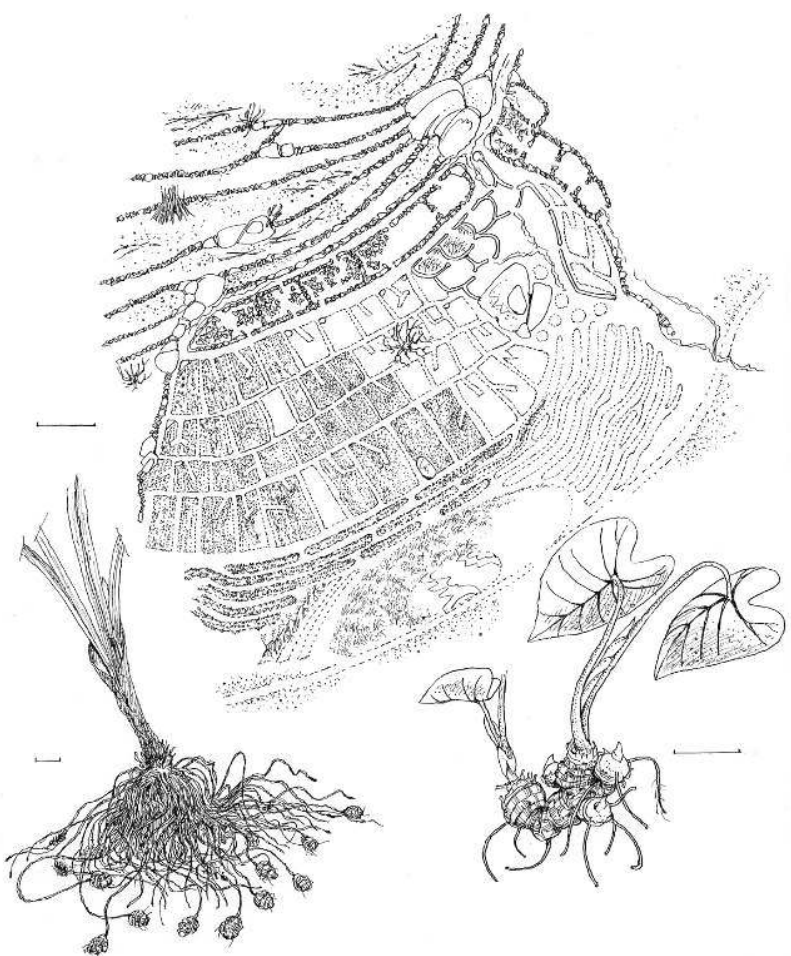

Haut : plan de la parcelle. Bas gauche : Souchet (échelle $1 \mathrm{~cm}$ ). Bas droite : Taro (échelle $5 \mathrm{~cm}$ )

Sur les champs de cases on relève un maïs ${ }^{8}$ ancien, des sorghos rouges hâtifs, différents légumes, des cucurbitacées et enfin les dernières ignames en fosse (Dioscorea abyssinica) (Figure 5). 


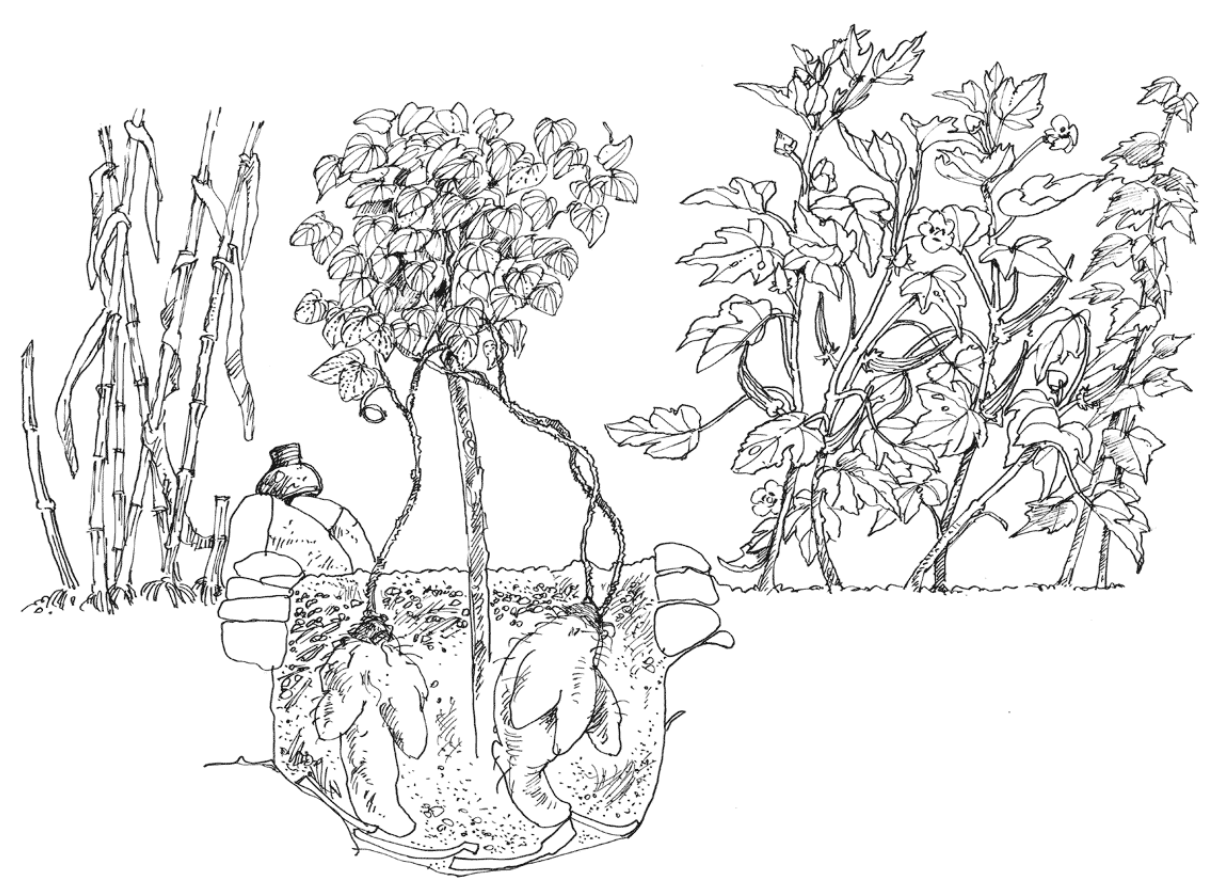

HAUT À gAUche : MAïs ; HAUT À dROITE : GOMBO

Avec l'achèvement de la conquête des terrasses par les sorghos zlaraway, la culture des ignames en fosse a peu à peu périclité tout en recouvrant, à proximité des habitations, un rôle essentiel de marqueur social. Seules les familles qui, sur chaque massif, combinaient ancienneté et possession de l'autorité politico-religieuse pouvaient en disposer. Il était interdit de vendre et de transporter dans les massifs des boutures d'ignames, non plus que de prendre l'initiative de descendre en plaine déterrer des ignames sauvages (Dioscorea abyssinica) pour les bouturer sur le massif sans l'accord du chef. En effet lui seul (Mofu Duvangar) pouvait décider d'une telle opération, dans le cas où le stock des ignames viendrait à baisser sur le massif et que des familles patriciennes s'en trouveraient dépourvues. Le chef, aidé de ses notables tenait un décompte minutieux de toutes les ignames de sa juridiction. Chez les Mofu, les mbidlew, clans écartés du pouvoir, pouvaient néanmoins prétendre à s'élever socialement en empruntant au chef ou à un notable une bouture d'igname avec obligation de rendre l'équivalent. Malheur alors à celui qui ne pouvait tenir son engagement; on lui arrachait ses biens, à l'exception de ses semences (Seignobos 1992). Chez les Kapsiki seules les familles de notables disposaient d'ignames en fosse (doniya). Leur bouturage rendait compte d'une aussi grande complexité de gestes que chez les Mofu. Retirer l'igname de terre obligeait à creuser loin du tubercule afin de ne pas le blesser, à l'aide d'un plantoir spécifique (jalla). Les ancêtres étaient censés surveiller "leur» patrimoine igname pour qu'il ne soit pas dilapidé. Certains vieux informateurs, à Sir et à Mogodé, m'avouaient passer beaucoup de temps à récupérer des têtes d'igname (le haut du tubercule) prêtées pour qu'à leur mort, ils puissent remettre cet héritage à leurs fils aînés. Pourtant on entend ici et là des Mofu, Mafa et Kapsiki s'interroger sur ces pratiques et sur l'importance donnée à cette igname dont ils confessent en aparté n'apprécier que modérément le goût. 

Hallaire (1991) l'estime en moyenne autour de 20 pieds à l'hectare ; C. Seignobos (1982), pour la seule cuvette du mont Ziver entre 20 et 35 arbres/ha; S. Dury (1991), sur le versant oriental de Oupay, à Moutchkor, domaine mafa très peuplé, à 58 arbres/ha. Le choix de la classe des jeunes pousses biaise à chaque fois le décompte.

Sur les basses pentes des terrasses, on relève Faidherbia albida élagué tous les trois ans et renouvelé tous les douze à quinze ans, Acacia sieberiana, Acacia polyacantha. Les terrasses hautes sont plutôt laissées à Ziziphus mauritiana (Figure 6), en taillis furetés. Dans l'extrême nord des Mandara, les cultivateurs disposent des pierres sur la souche des Ziziphus afin qu'elle s'étale en multipliant les rejets. Ils les cerclent alors pour les maintenir verticaux. La production de jujubes devenant moins essentielle au siècle dernier, les populations vont alors hésiter à privilégier les fruits ou les perches.

Figure 6 : Holarrhena floribunda et Ziziphus mauritiana (pays matal)

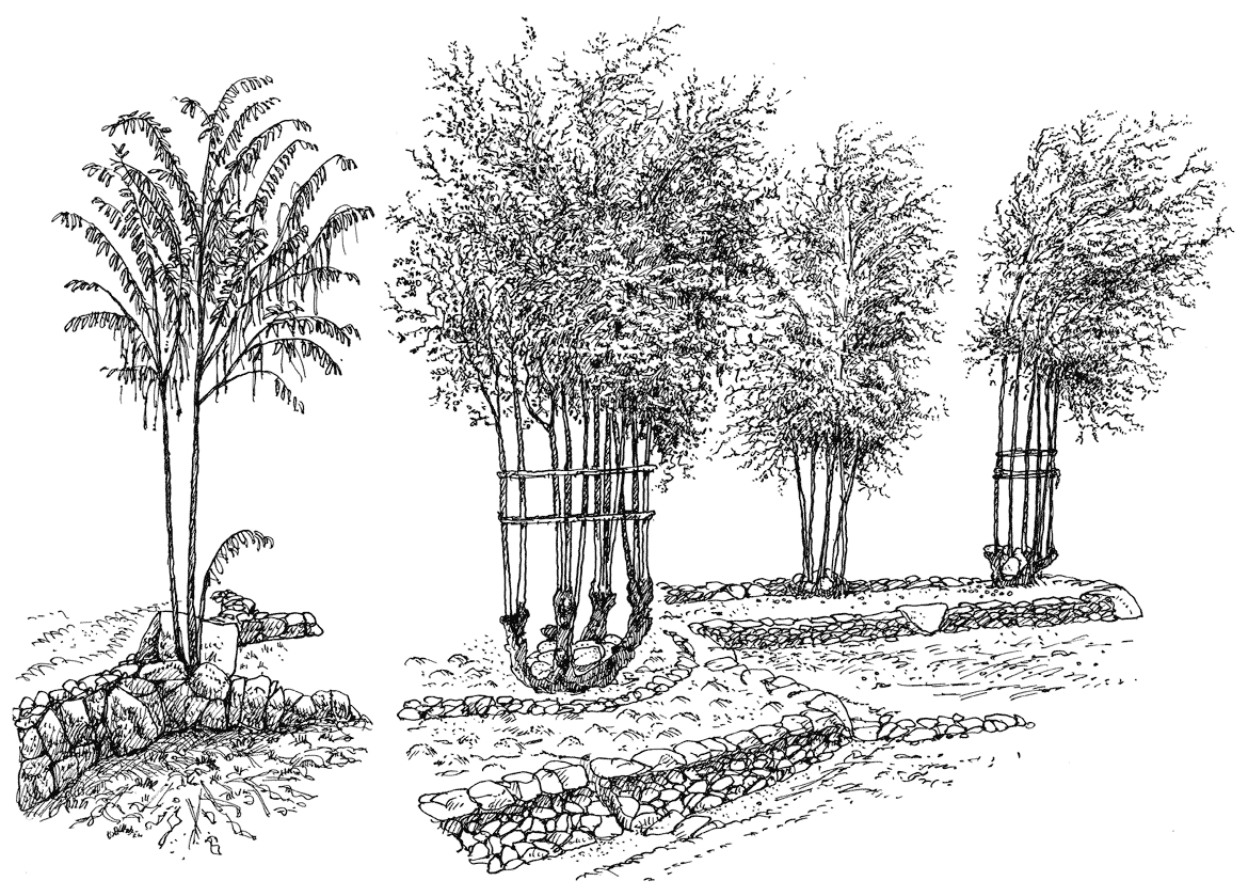

$\mathrm{Au}$ pied des murs des terrasses poussent généralement des Grewia spp., objets d'appropriations. On cantonne dans les rochers les arbres à larges houppiers et une gamme de Ficus inféodés à ce milieu, dont nous aurons à reparler.

\section{Des modes culinaires montagnards encore préservés}

\section{Les céréales}

Après un passage au moment de la soudure de sorghos hâtifs, salaway crus, grillés ou en bouillie ${ }^{9}$, la boule de zlaraway constitue la nourriture de base. Avec le zlaraway, on pouvait aussi confectionner des bouillies.

Zamak (chez les Mafa Nord) est un mélange de farine de sorgho et de souchet, d'éleusine (mbretək), de sésame (gogom); Mehewed' (Mafa Nord) est composée de farine de sorgho 
avec laquelle on a fait macérer des fruits: tamarins, Ximenia americana, Diospyros mespiliformis... Toutefois le simple mélange d'eau et de farine de zlaraway est un reconstituant y compris pour les combattants lors de conflits de voisinage. Chez les montagnards, on trouve justement une catégorie d'aliments dite "farines à boire ${ }^{10}$ ». On fait griller du sorgho que l'on écrase ensuite avec de la pâte d'arachide, cette farine additionnée d'eau est chauffée pour obtenir une bouillie. On fait de même avec des farines de sorghos mélangées à celles de souchet, de jujubes... Une bouillie de consistance légère, à base de farine de zlaraway et de pâte d'arachide, plongée dans l'eau bouillante peut être consommée matin comme soir.

On consomme également la boule de mil pénicillaire souvent cuite à la vapeur (balasl) et une infinité de mets à base de farine de niébé.

Du statut de céréale de base, l'éleusine est passée à celui de céréale d'appoint, puis de céréale au service de stratégies de réserves alimentaires. Durant tout le XIX ${ }^{\mathrm{e}}$ siècle elle a constitué les couches inférieures, plus ou moins épaisses des silos à sorghos, conservée là trois à cinq ans, épargnée par les charançons. L'éleusine endosse la même rusticité et la même longévité dans les silos que le fonio (Digitaria exilis) de l'Afrique de l'Ouest. Cette petite réserve stratégique n'était pas négociable et même exclue des échanges entre voisins (Seignobos 2002 : 107). L'éleusine accompagne le sorgho, mais on la maintenait également en réserve pour la consommer l'année du petit mil et avec ce dernier. Les deux farines mélangées dans une certaine proportion conféraient à la boule un goût proche de celui de la boule de sorgho. Autrement dit on atténuait la saveur un peu aigrelette du mil pénicillaire, le « goût sorgho » étant le référent gustatif revendiqué.

Les différentes sociétés de céréaliculteurs montagnards ont toujours cherché à obtenir un surplus de grains pour l'année suivante. Néanmoins ces stocks différés d'un ou deux ans, parfois plus dans les Mandara méridionaux, l'éleusine exceptée, peuvent prendre mauvais goût et leurs préparations devenir collantes. À Bourrha, devant des jeunes qui dénigraient de telles réserves, un vieux Jimi s'insurgea contre ces palais délicats, affirmant que c'était là de la "nourriture » et que cela suffisait. Le goût de l'aliment de base, la boule, est moins mis en avant que sa texture dont on décrit la fermeté, la friabilité ou la nature collante. Le goût des sauces suscite, en revanche, de nombreux commentaires.

\section{Composition des sauces}

Le companagium reste dominé par les légumes-feuilles de Ficus et de certains niébés. Toutefois les feuilles des arbres sont moins sollicitées que par le passé en raison de la présence généralisée des gombos (Abelmoschus esculentus), rejoints, via le canal des Peuls, par Hibiscus cannabinus qui, en plus des fibres, fournit les feuilles. La culture des céréales entraîne avec elle un cortège de rudérales venues de la plaine, où elles sont mieux exploitées. Corchorus tridens (laalo mangaramho), C. olitorius (laalo yaasko) (Figure 7) sont épargnés sur les champs lors des sarclages. 
Figure 7 : Ceratotheca, Sesamum et Corchorus

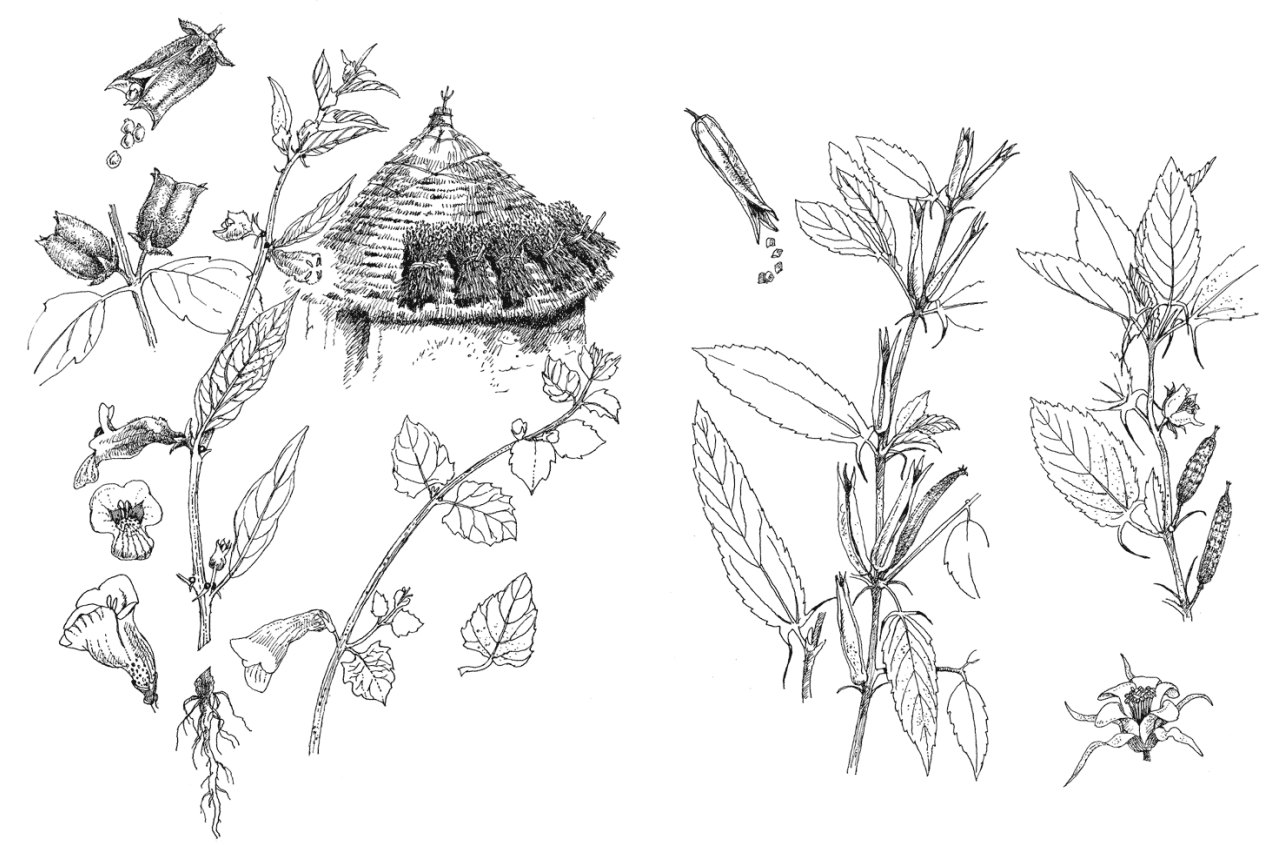

Bas extrême gauche : Ceratotheca sesamoides cultivé. Bas extrême droite : Ceratotheca sesamoides de brousse. Haut Sesamum indicum mis à sécher. Gauche : Corchorus tridens (Laalo mangaramho). Droite : Corchorus olitorius (Laalo dubbude)

Figure 8 : Physalis

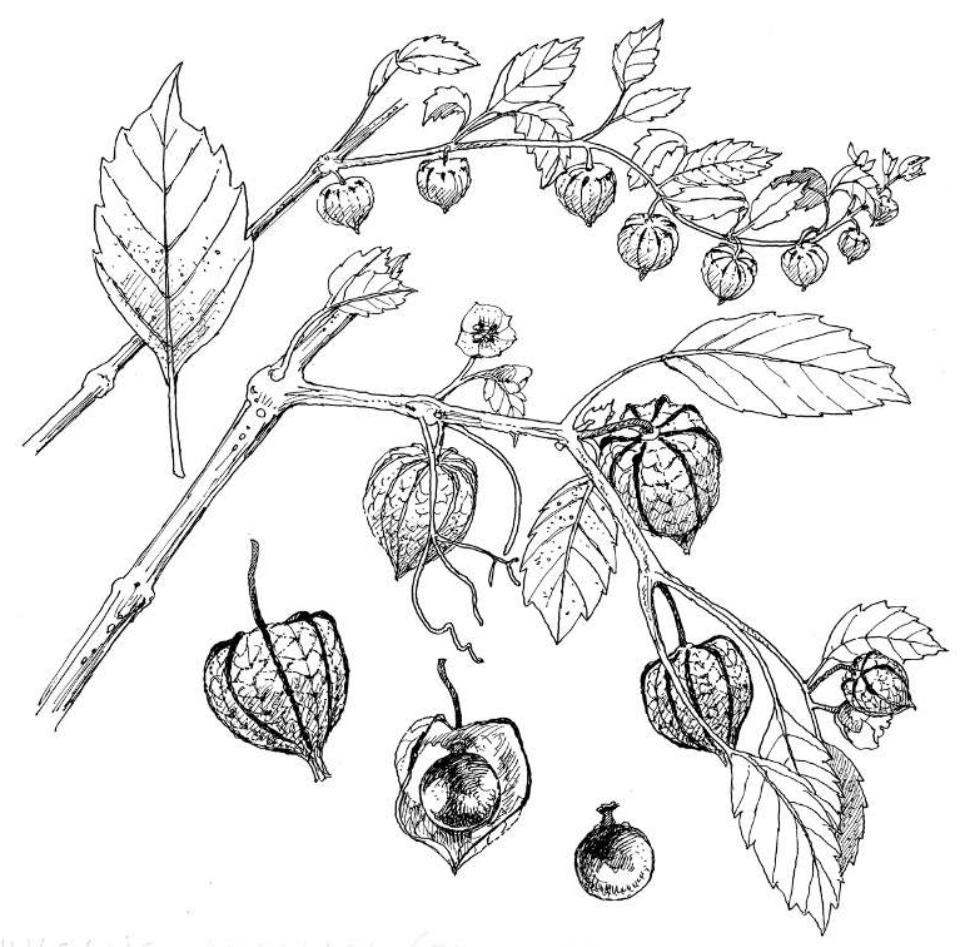

Haut : Physalis micrantha. Bas: Physalis angulata (paalelhi) 
On peut pratiquer trois à quatre coupes de leurs feuilles. On compte également un Ceratotheca sesamoides (Figure 7) (gubudo) sauvage et quelques Amaranthaceae plus récemment apparues. Avec Physalis micrantha et Physalis angulata (Figure 8) (paalelhi : qui porte de petites calebasses), on confectionne des sauces avec leurs feuilles et leurs fruits, sortes de baies jaunes à maturité. Sur le versant des Mandara, Cleome gynandra (Figure 9) (worbaaho) fait l'objet de préservations en marge des parcelles. Les sauces cuisinées avec ses feuilles additionnées de pâte d'arachide ne connaissent pas le même succès qu'en plaine. Je n'ai pas observé sur la montagne l'utilisation de Trianthema portulacastrum (ndeera nagge: gros ventre de vache), ni de Portulaca oleracea (Figure 11) (watataayel: le petit increvable) pour amalgamer d'autres brèdes séchées sous forme de boulettes, leurs feuilles charnues autorisant ce conditionnement. Ces sub-spontanées, nettement plus abondantes en plaine, concourent à atténuer l'acidité des sauces (Le Bourgeois \& Seignobos 1995 : 104). Durant tout le xIX siècle, les nouveautés culturales vont transiter par le monde peul qui occupe les plaines: ciibe (Sorghum mellitum), kondon (Musa sapientum), nouvelles arachides, nouveaux sorghos guineense, piments... Les condiments huileux reviennent de longue date aux boulettes de graines d'oseille de Guinée et la pâte de sésame alors que l'arachide a été récemment introduite sur la montagne (première partie du XIX ${ }^{e}$ siècle). Mais c'est la graisse animale qui jusque-là reste privilégiée dans les monts Mandara septentrionaux, du moins dans le discours, même si au quotidien on se contente de pâte d'oseille. Quant aux Mandara méridionaux on y fait encore et toujours appel aux courges oléifères et aux sésames.

Figure 9 : Cleome, Cassia et Portulaca
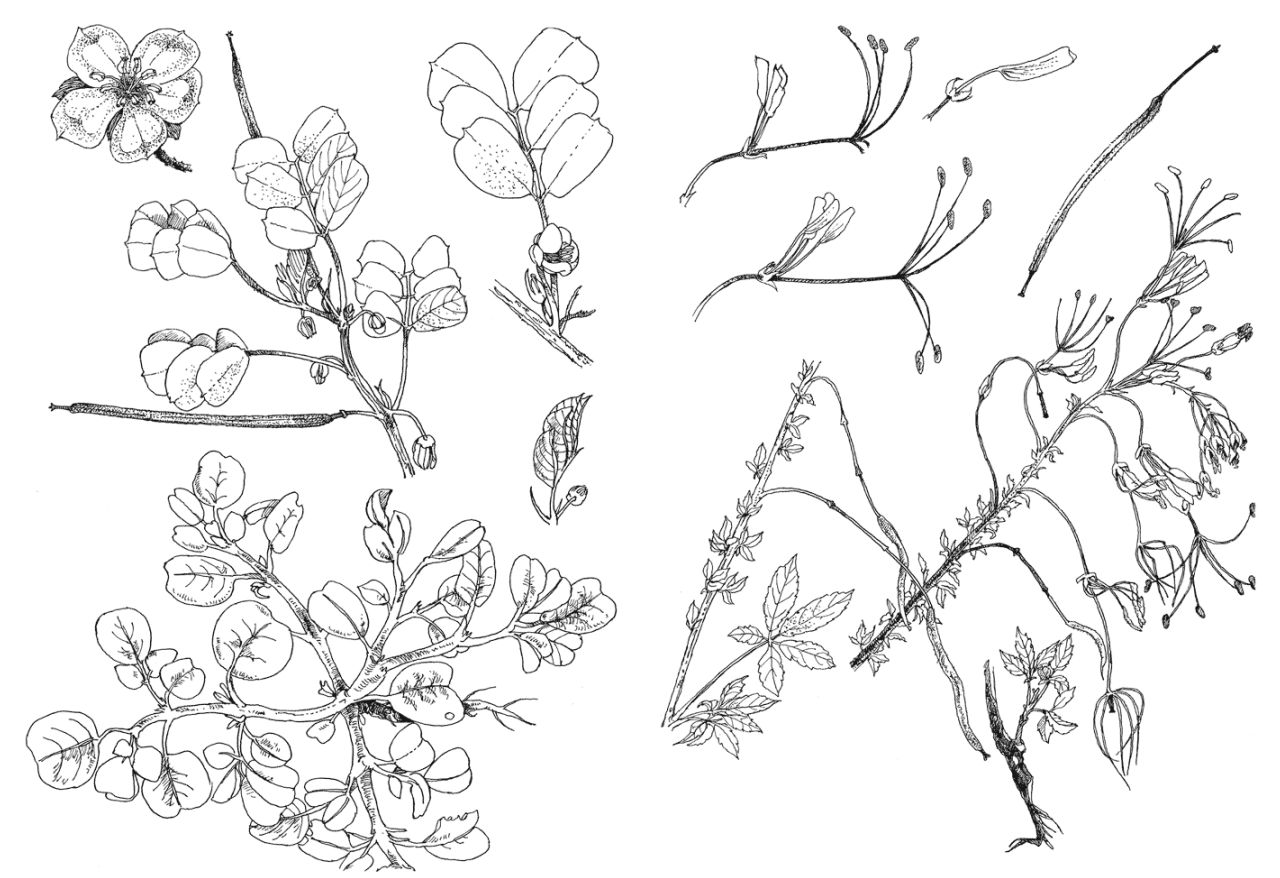

Haut gauche : Cassia obtusifolia (tasbaaho). Bas gauche : Portulaca oleracea Droite : Cleome gynandra ( worbaaho) 


\section{Viandes et graisses} sont grillés, d'autres sous formes de lanières sont mis à sécher suspendus par des cordes dans le corps de greniers-séchoirs. On conserve d'autres parties dans le mil même à l'intérieur du silo. Là elles sèchent, durcissent et doivent être mises à tremper avant leur préparation (Boisseau \& Soula 1974: 560). Chaque chef de famille cherche avant tout à obtenir de la «graisse». C'est le mbaza, la graisse, les os et cartilages en voie de décomposition. Le péritoine du bœuf sacrifié est bourré de la graisse des intestins avant d'être accroché à un arbre ou dans un silo pour le faire sécher. Une semaine plus tard on concasse et on broie le tout sur une plaque rocheuse proche de l'habitation. On le reverse alors dans des poteries spéciales, à engobe noir chez les Mafa (hurdada et baravak). On renouvelle l'opération plusieurs fois. La bouillie obtenue dispense un goût très prononcé qui vise à rehausser les plats. Une petite quantité sera alors battue avant d'être introduite dans une sauce dès lors de couleur crème, d'où son nom de "sauce blanche ». Nous l'avons chaque fois consommée avec de la poudre d'aubier de Grewia spp. Nos hôtes ont toujours insisté sur l'ancienneté d'une telle préparation.

Toutefois, le plat emblématique de la fête inclut des boulettes de cette graisse avec de la farine de niébé (diya en mafa) et un renfort d'oseille, de la saumure (hutsad), le tout mijoté.

La viande des fêtes (maray) a vocation à être distribuée. Les règles de partage, pour n'être pas immuables, servent toujours des hiérarchies familiales et celles d'alliances qui, elles, ne souffrent pas de manquements. En revanche la graisse et les « os » (tasl) restent au chef de famille. Il prépare lui-même les boulettes de graisse appelées valash, avec lesquelles on ouvre la nouvelle année, après les récoltes. Le mois qui suit reçoit l'appellation de lum valash (mois ou temps de la graisse).

On a toujours fait grand cas du bœuf du maray et autres fêtes du taureau, temps forts, festifs et religieux, des montagnards de Roumzou (Kapsiki) jusqu'aux Matal et Muyang. Toutefois l'élevage du «bœuf de case » ne devait guère toucher plus de $20 \%$ des chefs de massif qui, selon l'expression, "pleuraient le taureau maray» (kudə maray). Ce rituel ostentatoire avait lieu tous les trois ans, comme à Djinglia, ou tous les deux ans ou quatre ans dans d'autres massifs. Nourrir un taureau pendant deux à trois ans, fourrage et eau, représentait pour une famille un investissement énorme en temps et en pénibilité. Le bouc castré (dived en mafa) de trois ans, autrement plus répandu, se révèle le plus gros contributeur de graisse animale. On pratique de la même façon, l'estomac du bouc rempli de graisse, d'os et de cartilages pilés est suspendu à un arbre près de la concession. Cette graisse se conservait souvent, comme chez les Zulgo, dans de la cendre.

51 La chèvre est l'animal qui rend le plus de services, économiques comme liturgiques. Les montagnards méridionaux, les Kapsiki par exemple, en déterminent trois types. La petite, quasi naine, $k$ wa xola (= chèvre/Euphorbia unispina - qui, au contraire des autres euphorbes, ne grandit pas); kwə xhə (chèvre/maison) de taille moyenne et à robe beige et kwa mbarara 
(chèvre/Peul), la grande. On serait tenté de corréler les deux premières à Hircus reversus de la zone soudano-guinéenne, tolérante à la trypanosomiase et la moyenne à Hircus thebaïcus. La chèvre peule, en revanche, correspond sans équivoque, par sa taille, à Hircus mambrinus, la sahélo-saharienne. Depuis l'introduction tardive (fin $\mathrm{du} \mathrm{XIX}^{\mathrm{e}}$ ) des moutons, les montagnards pratiquent une ségrégation de leur élevage dans les pâturages comme dans les bergeries (Seignobos 2008). Les capridés et les poulets sont consommés par le biais d'une infinité de rituels et de fêtes.

On mange aussi le placenta des chevreaux après les avoir fait sécher trois jours. Le lait n'est pas pris en compte.

\section{Les condiments}

53 En 1930, les trompe-goût jouent encore un rôle important. Cette fonction était souvent assurée par le fruit de Lannea microcarpa. Ces fruits mis à pourrir dans la terre étaient ensuite placés dans des poteries hermétiquement fermées. Ce produit pouvait être utilisé sur plusieurs mois et la sauce ainsi aromatisée porte un nom. Le goût oscille entre celui de la viande fumée et celui du poisson séché. Ces arômes remplaçaient des produits rares (viande, poisson) avant que les marchés ne voient le jour en montagne et sur les piémonts, à la fin des années 1930. Le trompe-goût le plus constant, "le goût viande ", dans la sauce est encore apporté par des graines d'Hibiscus sabdariffa. Bouillies et gardées dans des poteries closes jusqu'à l'apparition de moisissures, elles sont séchées et écrasées. Cette farine grossière alors mélangée à de l'eau permet l'obtention d'une pâte épaisse qui devra fermenter dans une poterie hermétique. La pâte (mətuaz) sera ensuite transformée en boulettes de 6 à $7 \mathrm{~cm}$ de diamètre mises à sécher. Le produit final peut se conserver une année. Cet arôme incorporé pendant la cuisson est émietté au-dessus de la préparation, ce geste portant également un nom.

\section{Les mucilages}

Les Grewia spp., tout comme Lannea microcarpa sont réputés "commandés par les femmes ». Les mucilages relèvent essentiellement de Grewia villosa (sekwer), Grewia mollis (zlevad) et Grewia flavescens, dont on utilise les fleurs, les jeunes pousses, les fruits et les aubiers. On exploite les Grewia dès la récolte des sorghos rouges (salaway), avant que le petit bétail, friand de ses feuilles, ne soit lâché dans les champs. Les nouvelles pousses de Grewia récoltées se travaillent encore fraîches à la cuisine. On ôte précautionneusement avec une sorte d'écorçoir la partie externe de couleur brique. Puis on bat les tiges pour en détacher un aubier blanchâtre. Ces canons d'écorce, rassemblés en bottes de $60 \mathrm{~cm}$ de longueur, sont mis à sécher au soleil pendant une semaine. Certaines femmes les réduisent directement en farine en les pilant au mortier. On tamise le produit pour obtenir une poudre la plus fine possible. Grewia et gombo peuvent être pilés ensemble. Ce "gluant de Grewia " non seulement rend la sauce onctueuse, mais il renforce le goût, seul ou associé à des feuilles d'oseille, de Ficus ou encore à de la graisse animale. On incorpore le Grewia en le versant sur la sauce en cours de cuisson tout en tournant énergiquement le contenu afin d'éviter les grumeaux. Le Grewia, placé dans l'eau, peut aussi subir auparavant un battage qui crée une sorte d'émulsion avant d'être introduit dans la sauce. Les Grewia représentent le "gluant" de saison sèche par opposition aux plantes à mucilage fraîches Corchorus sp., Ceratotheca sp. et gombo qui abondent pendant la saison des pluies. 


\section{Autre type de consommation}

$$
\text { après cuisson à l'eau dans leurs coques, et du maïs jamais réduit en farine et que l'on }
$$
mange bouilli ou grillé, avec obligation de partage entre voisins.

\section{Les sucres}

À la question sur le sucre, les montagnards répondent souchet, grignoté comme en-cas ou sous forme de gâteau (matway en mafa). Les petits tubercules de Cyperus esculentus sont torréfiés, puis écrasés et mélangés à un peu de miel ${ }^{11}$. Ces nourritures offertes lors des fêtes sous formes de dons et contre-dons confortent surtout les relations des femmes, le souchet étant une culture réputée féminine.

I. de Garine (1988: 10) parle d'une «endo-cuisine " avec le sel et d'une " exo-cuisine » avec le sucre, qui serait consommé en dehors des repas et le plus souvent à l'extérieur de la maison. Le gâteau de souchet des montagnards s'offre hors des cercles familiaux, lors des fêtes. Les cannes de Sorghum mellitum sont consommées en quelques semaines, au début de la saison sèche, au cours de rassemblements de jeunes autour des places de danse et des marchés. Avec ces cannes sucrées, la grosse courge Cucurbita maxima (waygoore en fflde) partage la qualification de nourriture la plus sucrée (gun gunna'a en mafa). La chair cuite à l'eau peut être consommée seule, séchée elle se cuisine également dans un bouillon de viande. Le plus souvent mélangé en purée avec de la pâte d'arachide et l'incontournable niébé que les montagnards ne sauraient éviter, c'est un des rares mets consommé froid, et il prend alors une appellation spécifique en fulfulde: laawturu (Tourneux $2005: 258$ ). On l'offre à des invités à l'extérieur de l'habitation et en dehors des repas. Courge sucrée et pâte d'arachide représentent une association de propriétés gustatives et organoleptiques qui s'est révélée dès leur arrivée quasi concomitante (deuxième partie du XVIII ${ }^{e}$ siècle) dans les Mandara.

Dans les monts Mandara méridionaux les Gude se différencient du reste des montagnards par un encadrement politique qualifié - faute de mieux - de confédération. Ce degré d'organisation supérieur, perceptible jusque dans leurs villages qui présentent un aspect quasi « urbanisé », touche aussi la qualité de l'ensemble de leur culture matérielle. Ils se démarquent également au niveau de leurs comportements alimentaires et se rapprochent de leurs voisins de plaine musulmans peuls et des communautés hausa-kanuri. Les Gude manifestent une propension à consommer du sucre. Ils confectionnent une mélasse à partir de la pulpe de fruits de Vitex doniana (Figure 10) pour agrémenter de nombreuses bouillies. Elle relève d'un fond culinaire ailleurs disparu, dont nous aurons à reparler. Ils utilisent également pour les bouillies la pulpe sucrée du néré. Cordia africana (Figure 10) (papawa) emprunté aux Hausa à la fin du XIX ${ }^{e}$ siècle est semé dans les périmètres habités, où on le taille régulièrement. Ses fruits jaunes sont séchés et pilés. Après bouillissage, le jus est réduit en sirop ou en mélasse pour aromatiser des gâteaux à la farine de mil. L'agrosystème gude s'avère à la fois conservateur et ouvert. Les Gude disposent de la gamme de souchets (mandiviya) la plus complète. Ils consomment des sorghos à grains sucrés comme suku'n sanga, façonnés en boulettes avec du miel ou de la mélasse de Vitex, et qui se conservent une année durant. Ils déterrent les rhizomes de Burnatia enneandra que certains peuvent garder près des poteries de réserve d'eau pour des consommations différées en bouillie sucrée, associée à de la farine de sorgho et de la pâte d'arachide. Chez

Revue d'ethnoécologie, 5 | 2014 
les Gude également, les nourritures sucrées se partagent entre promis et promises, lors de mariages et à travers divers réseaux d'alliances.

Figure 10 : Cordia africana / fruits de Vitex doniana, Cadaba farinosa

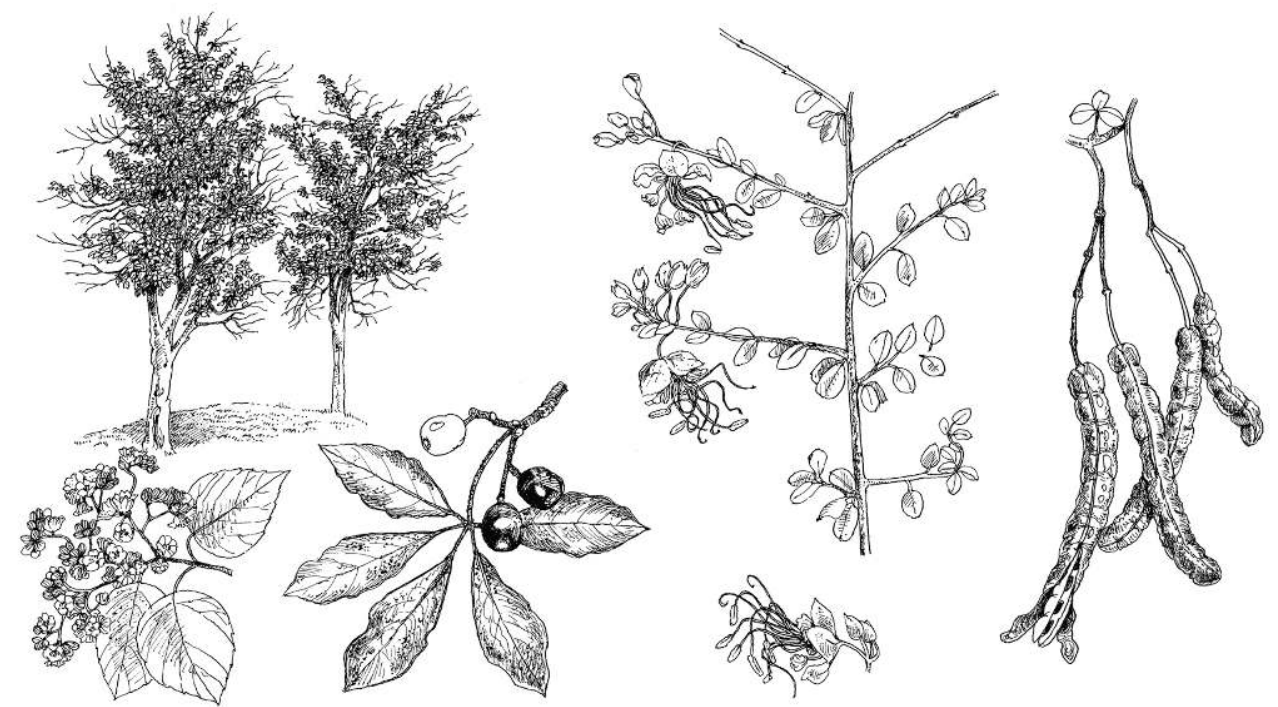

Cadaba farinosa (Figure 10) (cingcinghi en fufulde), arbuste croissant à l'ombre d'un arbre tuteur est désigné comme le "sucré des anciens ». Avant que le sucre industriel ne fasse son apparition dans les années 1930, les bouillies composées entre la fin de la période sèche et le début des pluies étaient aromatisées avec Cadaba farinosa. On faisait bouillir l'extrémité de ses bractées et de ses fleurs jaune vert ou on les broyait avant de les mettre macérer dans de l'eau. On en imbibait alors les morceaux de boule de céréales sèche que l'on remettait ensuite à sécher avant de les piler. La bouillie issue de cette farine appréciée de tous était sans doute plus courante en plaine. On la servait en en-cas au milieu de la journée ou pour des travaux en commun; les femmes âgées la réservaient à leurs petits-enfants.

Les plus friands de sucre, les enfants, le recherchent en brousse, dans les fruits, certains aubiers, le miellat des pucerons cristallisé sur les feuilles de sorgho. Les fruits sont toujours "un peu sucrés ", mais souvent terriblement astringents dans la mesure où on doit les consommer avant que les vers ne s'y mettent. S'opposeraient alors un sucré acide et un sucré doux fourni par les cannes de mil et le souchet, le miel venant le plus souvent en adjuvant à la pâte de souchet.

\section{Les bières}

Dans le passé la bière de mil ne coulait pas à flot, hormis lors de quelques grandes fêtes. Les vieux adultes se réservaient sa consommation. Nos informateurs rappellent d'ailleurs leur frustration lorsque jeunes ils ne recevaient la bière de la bouche des anciens qu'en pulvérisation, geste de bénédiction de la part des aînés (cesl cesle'e ou pish en mafa). Les premières bières étaient des bouillies alcoolisées servies chaudes. Avec la multiplication des sorghos rouges à tanins on fabrique une bière légère, brune et servie froide récemment appelée « bilbil »-brassée selon une recette venue des plaines ${ }^{12}$.

Les sorghos rouges donnant les meilleurs crus, la composition des malts évolue. Certains groupes des monts Mandara méridionaux ont maintenu les deux types de bières, la 
bouillie alcoolisée blanche (furdu) étant plutôt consommée chaude pendant la saison fraîche. Au début du $\mathrm{xx}^{\mathrm{e}}$ siècle apparaissent de nouvelles catégories de bières. Celle des Kirdi Mora, le valawa (caiilcédrat), qui justement intègre dans la bière une macération de liber de cette essence, va se développer chez leurs voisins, Breme, Urzo et jusqu'à Maroua. Son arrivée sur les marchés s'est accompagnée de conflits batailleurs entre tenants des anciennes bières et affidés de la nouvelle. La fin de la confiscation de la bière par la gérontocratie sera effective au moment de la descente en plaine et avec l'arrivée des marchés. Les sociétés montagnardes ont dû lâcher du lest en autorisant les femmes à commercialiser de la bière de sorghos, sorghos devant être achetés sur les marchés, préservant ainsi ceux du grenier. Les montagnards, en étendant l'accès à la bière de mil du religieux à l'ensemble des relations sociales et jusqu'à sa commercialisation, sont enfin devenus - ô combien tardivement - des « sociétés à bière ».

\section{Un agrosystème diversifié sans sorgho dominant ( $\mathrm{x}^{\mathrm{e}}-$ XVII siècle)}

\section{La mise en place des rotations biennales}

L'exploitation intégrale des monts Mandara et le passage à une agriculture intensive représente une étape essentielle, que nous ne sommes pas en mesure de réellement dater (peut-être entre le XV et le XVII ${ }^{e}$ siècle). Le recours aux généalogies, ces « chartes légales » de groupes d'agnats, issues de constants remaniements ne servent pas de comput du temps.

64 Le résultat a été une mise en terrasses intégrale des Mandara septentrionaux, s'accompagnant d'un cloisonnement corrélatif des communautés. Toutefois ces constructions n'ont jamais servi des projets collectifs, elles passent toujours par des «techniques résolument individualistes» (Hallaire 1991: 35). Leur élaboration peut néanmoins s'avérer rapide ${ }^{13}$ pour élever, même sur de forts dénivelés, des banquettes allant de quelques dizaines de centimètres à quelques dizaines de mètres. Elle s'appuie sur l'épierrage ou le refaçonnage sur place de pierres. À chaque fin de saison sèche, on les répare, on corrige le tracé, maintient les contrepentes plus ou moins marquées vers le mur du haut afin de mieux conserver l'eau et la contraindre à percoler dans l'escalier des terrasses. Le mur de la terrasse (menge ley en mofu = « le piège du champ ») sert bien là à retenir la terre arable (Seignobos \& Tchotsoua 2012). On peut difficilement ne pas lier le phénomène d'enterrassement avec certains seuils de peuplement. Selon un mécanisme constant et sur de nombreux siècles, les royaumes des plaines du circum tchadien ont absorbé et refoulé d'innombrables groupes sans toutefois provoquer de fortes vagues migratoires, excepté peut-être au XVIII ${ }^{\mathrm{e}}$ siècle marqué par un fort épisode de sécheresse (Maley 1981 : 67). Celles qui se présentent parmi les dernières au XVIII ${ }^{\mathrm{e}}$ sont composées de « suiveurs de cucurbitacées » (Seignobos 2009). À cette époque le Diamaré est peuplé de " petits groupes indépendants rétifs à toute concentration étatique minimale » et qui avancent ou fuient en se repoussant les uns les autres (Marliac 1995 : 207).

La mise en terrasses, ou est la conséquence, d'une accumulation sur place de la population ${ }^{14}$. Les encadrements politiques de ces communautés montagnardes se montrent incapables de créer un exutoire pour leurs excédents de peuplement. Elles avaient pour seul recours d'intensifier leur système de production (Pélissier 1995). 

fluidité de circulation des hommes montés sur poneys (cheval des rochers, $d u$ proh en kapsiki), la fin aussi de la déambulation du bétail bovin (les taurins) que les terrasses vont condamner. La jachère n'a plus cours, poussant au choix de la rotation pour des cultures productives et une gamme de cultivars mieux étoffée. À cette époque les montagnards façonnent tout à la fois les sols et les plantes appropriées. monts Mandara et, au-delà, de la venue du sorgho. Au contraire de ceux concernant les éleusines et les petits mils, les récits intéressant les sorghos relèvent de constructions historico-mythiques qui, malheureusement, passent par le biais de leur structure gigogne.

Sur le massif mafa de Magoumaz, le héros civilisateur Shiler (Martin 1970 : 33-34), venu de Soukour sur le flanc occidental, apporte dans son carquois le sorgho zlaraway. Les autochtones madambrum n'auraient cultivé que du mil pénicillaire. À l'arrivée de Shiler ils auraient été décimés par une préparation de bière à base de faux épis de petit mil atteint de charbon (gwadafa en mafa). Toutefois un autre mythe revendiqué par les Madambrum présente ces derniers comme prenant possession de la région en se débarrassant des groupes forgerons autochtones qui, eux aussi, auraient succombé à une bière de mil pénicillaire.

Les cultures majoritaires qui nourrissent le groupe au quotidien participent à son identité devenant ainsi pour lui consubstantielles. Dès lors on comprend que l'adoption de nouvelles cultures, qui ne peuvent provenir que de tiers, entraîne des choix conflictuels au sein de ces sociétés, pouvant aller jusqu'à l'affrontement idéologique. On touche ici au religieux, le lien avec les ancêtres risque d'être rompu. Une lutte s'engage entre deux factions, celle qui apporte la nouvelle culture réussit à rallier une partie des autochtones, l'autre s'y refusant obstinément. Cet affrontement passe par des formes de «propagande » qui s'attachent à porter le discrédit sur l'une ou l'autre production identitaire. La mise à l'écart d'un cultivar est le plus souvent victime de discours orchestrés socialement et politiquement. Un groupe finit par l'emporter grâce à sa vitalité et à sa descendance prolifique imposant ainsi sa légitimité. La culture écartée sera ensuite présentée comme la cause de l'échec de l'autre.

70 Nous donnerons deux exemples. C'est moins la petitesse des grains de l'éleusine et ses faibles rendements qui seront incriminés, qu'une nocivité avérée. La bière d'éleusine est plus forte que celle de sorgho. Ainsi les actuels Podokwo qui chassèrent de leur massif les Gelebda vers l'ouest, dans les Gwoza hills à la frontière du Nigeria, les accusent d'avoir été saisis de folie après l'ingestion de bière d'éleusine (mburtwa) et de s'être enfuis. Ce type de formulation occulte en général un refoulement violent précédé de massacres. Lorsque les clans Shiler («nouvelle génération » en Mafa) prennent le pouvoir à Magoumaz, tuant les Madambrum grâce à leurs arcs, ils accusent la maladie du petit mil de les avoir décimés.

71 La montée en puissance des tenants des sorghos va pousser le cultivateur à rechercher un équilibre à travers une rotation binaire. Elle relèvera alors autant d'un calcul agronomique que d'une négociation sociale. Cette «stratégie » a encore plus de chance de se réaliser qu'elle succède à une précédente rotation binaire petit mil/éleusine qui selon toute vraisemblance n'a pu que relever, elle aussi, d'une charte de cohabitation entre deux groupes. 
majorité de traditions orales fait venir les sorghos zlaraway de l'ouest. Il est toutefois impossible de se prononcer sur la date de leur introduction non plus que sur l'échelle de temps de leur acclimatation. La certitude, en revanche, tient à l'adaptation effective de ces sorghos aux "sols squelettiques» des terrasses au point qu'ils apparaissent comme inaptes à la culture en plaine, et même sur les piémonts ${ }^{15}$. Le zlaraway a pu se maintenir longtemps dans les abords des maisons, puis envahir les terrasses existantes et devenir ensuite, comme sorgho des lithosols, le moteur d'une intensification de l'agriculture qui accompagnera la mise intégrale en terrasses des massifs du haut Mandara.

Chaque groupe montagnard dispose de trois à sept types de zlaraway, des caudatum et des durra-Bicolor à panicules allongées mi-compactes, à graines globuleuses jaune mat, ce qui donne leur appellation en français : "sorgho jaune ${ }^{16}$ ». Leur hauteur est remarquable, 4 mètres et plus, fournissant un complément appréciable pour les feux des cuisines. Ils doivent être confortés au moment de l'épiaison et sont attachés par trois ou quatre aux deux tiers de leur hauteur. Ces sorghos, à la différence de ceux des plaines, sont peu spécialisés. Les montagnards leur assignent même une qualité de polyvalence. On reste surpris que chaque communauté ait multiplié des variétés semblables, même cycle, même rendement, répondant aux mêmes besoins : grains consommables crus ou grillés, en boule, en bouillie, en bière, aux bas de cannes généralement sucrés. Dans la réalité, chacun répondait à des critères particuliers : meilleur enracinement, cannes plus courtes, résistance à la verse et à certains prédateurs.

Avec l'arrivée d'une gamme de sorghos (Figure 11), les salaway (Sorghum caudatum) venus de l'est, des plaines du Logone, la spécialisation va apparaitre. Ces sorghos rouges hâtifs ou précoces vont compléter la production de zlaraway à partir des champs de case et sur les piémonts. Les premiers adoptés se révèleront être des sorghos anti-acridiens. Particulièrement amers ils vont rebuter les vols de criquets et d'autres déprédateurs. On aura recours à eux, dans certains massifs, pour une fonction particulière, de protection des zlaraway, trop vulnérables, qui commencent à être cultivés sur certaines terrasses exposées, en les noyant parmi eux ou plutôt en formant des écrans protecteurs. Durant cette période de pression foncière, à la fin $\mathrm{du}$ XVII ${ }^{\mathrm{e}}$ siècle, l'arrivée des sorghos rouges a permis de renforcer l'intensification de l'agriculture. Dans ce lot de sorghos précoces apparaissent des écotypes particuliers à panicules semi-lâches, à grains blancs, gris, voire franchement bleus comme à Gadala, Boudoum (Seignobos \& Iyebi-Mandjek 2000). Avec ces sorghos les montagnards ont l'opportunité de récupérer des zones ombreuses qui auparavant ne pouvaient être vivifiées, comme les piémonts occupés par un liseré de grands caïlcédrats refoulés des terrasses. Sous leurs vastes houppiers sur les piémonts en face de la plaine de Gawar pousseront ces sorghos ombrophiles ${ }^{17}$. On ne peut conserver leurs panicules dans les greniers aussi serviront-elles pour la soudure et pour le brassage de bière. Nombre d'entre eux seront opportunément reconvertis en sorghos de rituels. Le plus exemplaire est un sorgho à grains gémellés blancs, cultivé et consommé par les seuls jumeaux ou parents de jumeaux, et ce depuis les Daba jusqu'aux Mofu Nord.

Figure $11 \mathrm{a}$ : Sorgho zlaraway (pays mafa) 


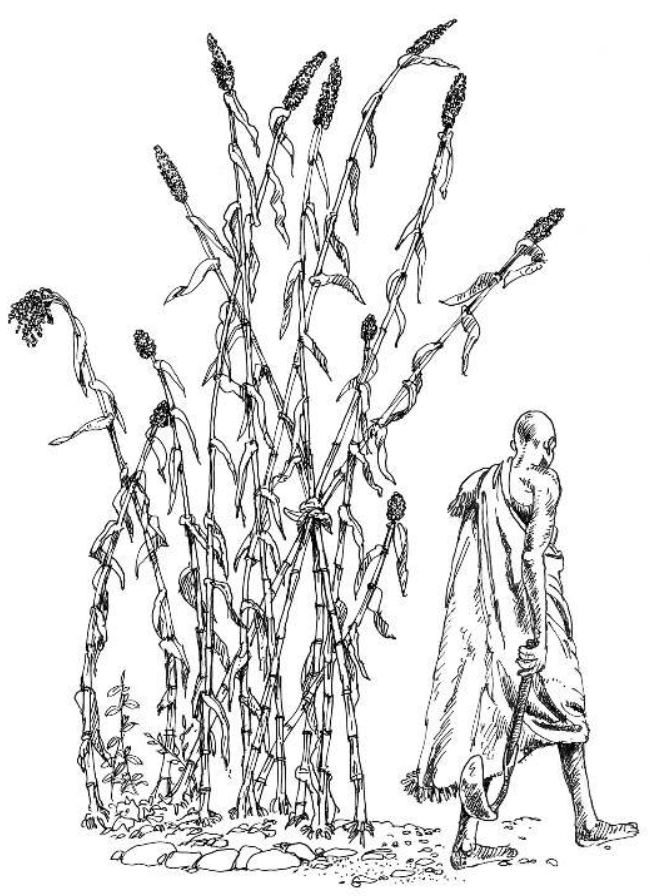

Figure $11 \mathrm{~b}$ : Sorghos de montagne
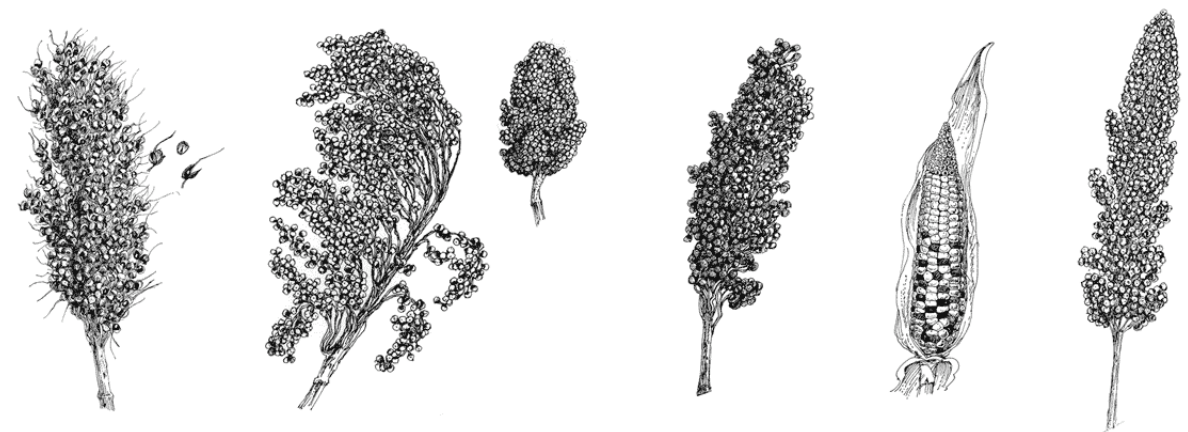

Mafa : sorgho à poils, zay kri (giziga) ; sorgho d'ombre ; sorgho rouge de type njigaasi S. durrha caudatum ; sorgho noir, metarey, (mofu) ; maïs (monts mandara) ; sorgho de montagne, cerge / zlaraway (mofu)

Si les salaway sont venus seconder les zlaraway acclimatés sur la chaîne, les zlaraway ont à leur tour permis la colonisation, plus tardive, de tous les massifs-îles à l'est, à l'avant des monts Mandara. Ils ont favorisé l'achèvement de leur mise en culture, ce qui explique parfois l'impression de colonisation récente de ces petits massifs.

Les sorghos géants (Figure 11), zlaraway secondés par les salaway, offrent des rendements incomparables par rapport à ceux des éleusines et des petits mils, encourageant des constructions de greniers ostentatoires comme les immenses silos chrysalides de 5 à 6 mètres de hauteur chez les Matal de Zouelva et de Gwalda. Zlaraway envahit le système nutritionnel et devient le symbole de l'abondance sans oublier son corollaire : l'angoisse de le perdre, ce qui ne manque pas d'entraîner une véritable forme de dévotion envers ces sorghos. Avec les zlaraway émerge et s'affirme l'idéologie du grand cultivateur. Chez les Gude, Jimi, Bana, Kapsiki, on honore par des chants ceux qui remplissent leurs greniers comme on raille les paresseux (Hallaire 1991 : 194). 
Figure 12 : Aire des silos du chef matal de Zouelva protégée par une végétation d'Acacia ataxacantha (début $\mathrm{XX}^{\mathrm{e}}$ siècle)

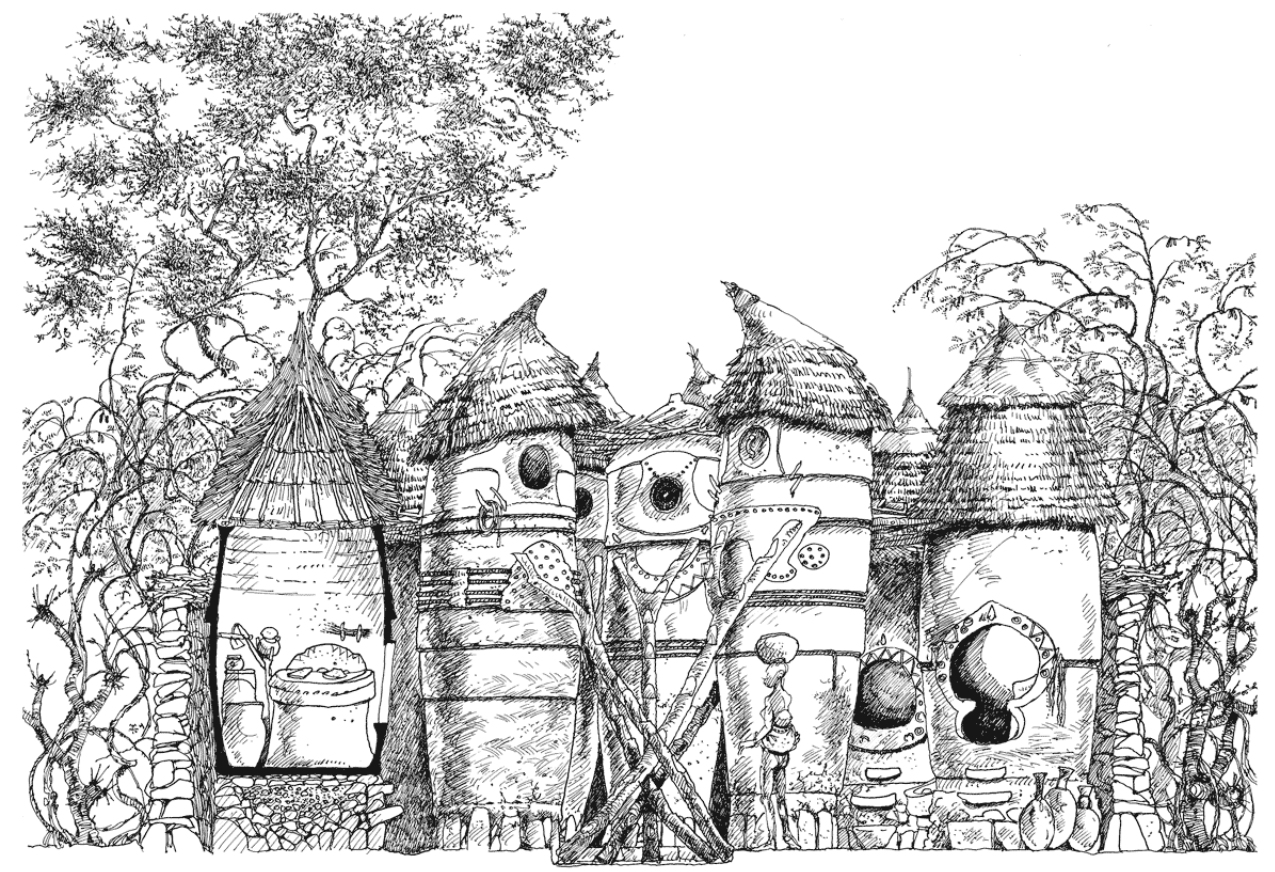

77 On se doit de ne pas omettre les sorghos de dissuasion. Ils ont constitué dans le passé une gamme, zlaraway et salaway confondus, très travaillée par les montagnards. Nous citerons certains que nous avons encore pu observer. Chez les Mafa de Mahoura, le dungdu semé en limite des parcelles assurait une protection contre les vols d'oiseaux et les incursions de singes. Le ndrim lohov des Daba du Popologozom, épargné par les cynocéphales, était réservé aux lopins marginaux, tout comme le daw ozibek des Mboku, ou encore le magoda des Gavar que l'on semait dans les anfractuosités des éboulis de rochers. Le xa keri (= sorgho du chien) des Bana, au grain grisâtre et fripé, était à ce point amer qu'on ne lui connaissait aucun ravageur. Également répartis le long des sentes, ils dissuadaient ainsi les grappilleurs de panicules aux grains encore à l'état laiteux. Chaque massif chérissait ses sorghos dissuasifs dont certains approchaient la notion de poison, comme les voh des Daba. Ils pouvaient, par leur concentration en tanins, entraîner la mort du petit bétail. On disposait les sorghos les plus agressifs sur les lignes frontières des quartiers.

De ce panel on extrait des sorghos à bières dits «sorghos noirs ", de fait rouge grenat: ndri perghi en hina, metərey en mofu Gudur... Il existe encore des sorghos aristés ${ }^{18}$ dont les glumelles prolongées d'une aiguille protègent des attaques aviaires. Les « poils » tombent après maturité, dans le cas contraire les panicules doivent être battues dans des sortes de sacs. Un bouillissage ou une longue macération dans une eau additionnée de sel de potasse précède l'ingestion de ces sorghos.

On assiste parallèlement à un dessaisissement de cultures antérieures comme les Eleusine coracana aux variétés encore nombreuses et aussi au recul des techniques culturales qui les accompagnent: semis à la volée et en sec avant les premières pluies. Le nombre de mils pénicillaires resterait constant, entre trois et cinq. Les Mafa reconnaissent encore aujourd'hui n'tamas yar, n'tzmas diya (niébé), dehere et medere, et les Kapsiki de Sir : merhbə shinti (poil), m. waa (lait), m. məvə (naja). 

abyssinica) refluent également peu à peu vers les habitations. Cette période enregistre également le déclin des Lamiaceae. Comparée au rendement des nouvelles céréales, leur production devait être jugée trop irrégulière, une partie des stolons se perdant en terre. Leur culture, en revanche, prospérera jusqu'au début du $\mathrm{xx}^{\mathrm{e}}$ siècle dans les Mandara méridionaux, dans des terroirs moins contraints en espace et plus arrosés.

81 L'arrivée de nouvelles cucurbitacées renforce de façon significative le stock des cultures existantes. Le XviII ${ }^{e}$ siècle aura été le temps de la culture des courges dans les monts Mandara. Tous les récits étiologiques relevant de courants migratoires venus du nord et du nord-est décrivent des groupes ayant à des degrés divers un rapport avec les cucurbitacées ${ }^{19}$. Par la suite, durant tout le xix ${ }^{\mathrm{e}}$ siècle la conquête peule des plaines, qui se fait au détriment du royaume du Wandala, va interdire tout mouvement de population vers les Mandara. On enregistre seulement des remontées sur les massifs à partir des piémonts de groupes dont l'élément décepteur de leurs récits d'installation intéresse des sels solides et des natrons.

Les premières migrations de cet ensemble suivent exclusivement des calebasses, métaphore dominante de ces mythes d'installation. Elles partent du nord de Waza pour aboutir en pays podokwo. Les Podokwo de Moukouléhé se laissent guider par les linéaments d'une tige de calebasse (Lagenaria siceraria) (Lembezat 1952 : 43). Plus avant sur la montagne, chez les Matal de Gwalda, on revendique également le suivi d'une calebasse. À chaque étape elle fructifie, puis elle repart et sa tige montre le chemin «comme un serpent » jusqu'à l'établissement final (Juillerat 1971 : 64).

Logone enfin, dans le pays muzuk, le thème de la cucurbitacée, tout en empruntant des schèmes narratifs différents, caractérise une grande famille migratoire. De nombreux groupes vont migrer vers les Mandara en suivant une courge qui roule ou vont se séparer à la suite d'une querelle à propos du partage d'une grosse cucurbitacée (Cucurbita pepo) ou encore après un conflit concernant l'empiétement de cette même courge sur une limite. Chaque variante figure le blason d'une sous-vague migratoire qui se revendique d'un fond commun de peuplement. La courge a pu jouer ce rôle en raison de sa pertinence historique et économique permettant de crédibiliser les récits (Seignobos 2009).

Dans les monts Mandara, les courges se partagent en deux groupes, celles anciennes qui se développaient en partie sur les toitures, soutenues par de pseudo-paniers. Elles sont dites courges des hommes - sous-entendu des autochtones. On les oppose à celles venues ultérieurement de la plaine et que l'on désigne aujourd'hui comme courges des musulmans; la plus productive parmi elles reste Cucurbita pepo (C. maxima).

Les cucurbitacées reconnues comme les plus anciennes incluent surtout de petites courges oléifères telles que Cucurbita sp. cf. Citrullus lanatus. Elles ont pendant longtemps fourni la base oléifère de la montagne. Dans les Mandara méridionaux, Citrullus lanatus, teta en daba, représente une véritable relique. Les Daba ont baptisé leur rotation biennale culturale «l'année de teta» et «celle qui suit teta» (Hallaire 1991: 165). Cette culture « commandée » par les hommes car devenue cultuelle est produite l'année de la femme. Momordica balsamina, variété de petite cucurbitacée au fruit vert et rouge, fait l'objet d'une consommation plus abondante les années peu pluvieuses. Le goût sucré en serait plus prononcé (Le Bourgeois \& Seignobos 1995 : 107). Même les coloquintes aux feuilles scabrides et aux fruits marbrés de vert et de blanc étaient prises en compte dans l'alimentation. Si Cucurbita maxima représente l'abondance, la coloquinte renvoie à une 
nourriture indigente. La prise de pouvoir à Maroua par les Giziga sur le chef de Dougwoy trouverait son explication dans la pingrerie de ce chef qui ne donnait à son peuple que des coloquintes cuites à l'eau.

Le parc arboré (Figure 13) est plus que jamais composé d'arbres susceptibles de pousser dans les rochers sans que leurs houppiers ne gênent les cultures : tamarinier, caïlcédrat, Lannea et différentes espèces de Ficus. Diospyros mespiliformis et Syzygium guineense prospèrent plutôt près des points d'eau. Les autres arbres sur les terrasses sont, en revanche, taillés. Les Ziziphus toujours en taillis bas, Vitex doniana, Acacia spp., Ficus sycomorus sur les basses terrasses bénéficient d'une taille en têtard haut. Il convient de mentionner des parcs saccharifères composés de Vitex doniana chez les Bana, les Jimi et les Gude, véritables archéophytes qui ont jadis été répandus sur une grande partie des monts Mandara et également en plaine.

Figure 13 : Les monts Mandara (paléo-mofu) XVII siècle

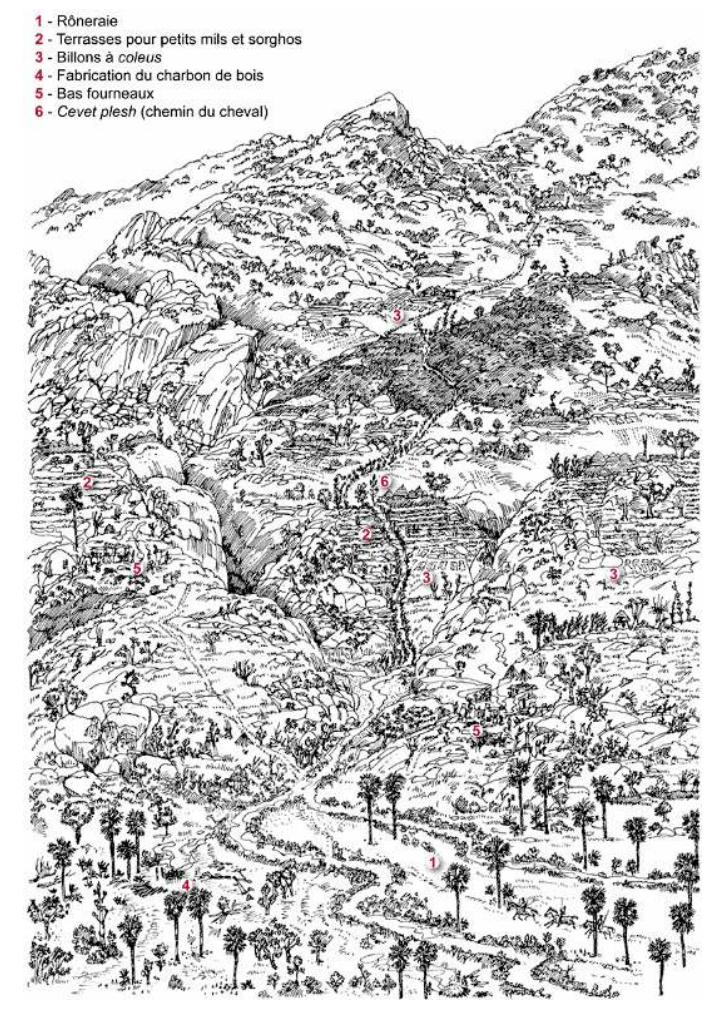

La grande transformation dans le paysage arboré est l'arrivée en montagne de Faidherbia albida. Jusque là l'arbre de restitution agronomique sur les Mandara avait été Acacia polyacantha en peuplement sur les fonds de talwegs et les premières terrasses. Faidherbia est apparu ${ }^{20}$ en concomitance avec la présence des zébus élevés chez les Peuls des piémonts (Fulbe baamle i.e. Peuls vivant auprès des païens), là bien avant la conquête peule des plaines du début du XIX ${ }^{e}$ siècle. Par le biais des graines contenues dans la panse des zébus, les Faidherbia vont gagner les terrasses, revendiqués au départ comme propriété des chefs de massif qui, les premiers, s'étaient portés acquéreurs de ces nouveaux bovins (Mofu Nord, jusqu'à la fin du xix ${ }^{e}$ siècle).

Les populations qui affichent leur arrivée sur les monts Mandara à la suite d'un bovin depuis la plaine, alimentent un mythe archétypal que l'on rencontre à Moukouléhé, Douroum, Douvangar (Vincent 1991), à Way-Ziver (Seignobos 1988 : 129), mais aussi chez 
les Mada, à Wazang et même à Goudour. Dans ce mythe commun à la plaine et à la montagne, la nature du bovin est rarement spécifiée, des taurins jadis également élevés en plaine. Ne pouvant déambuler librement sur les terrasses, les taurins (Bos taurus (Figure 14) vont peu à peu disparaître. Ils feront place à un élevage claustré dans une étable surcreusée et ensuite murée, le zébu (Bos indicus) taurillon répondant mieux au nouveau rôle assigné au gros bétail. Les taurins se maintiendront dans les Mandara méridionaux chez les Kapsiki, les Bana et les Jimi (Seignobos \& Thys 1998).

Figure 14 : Taurins Kapsiki

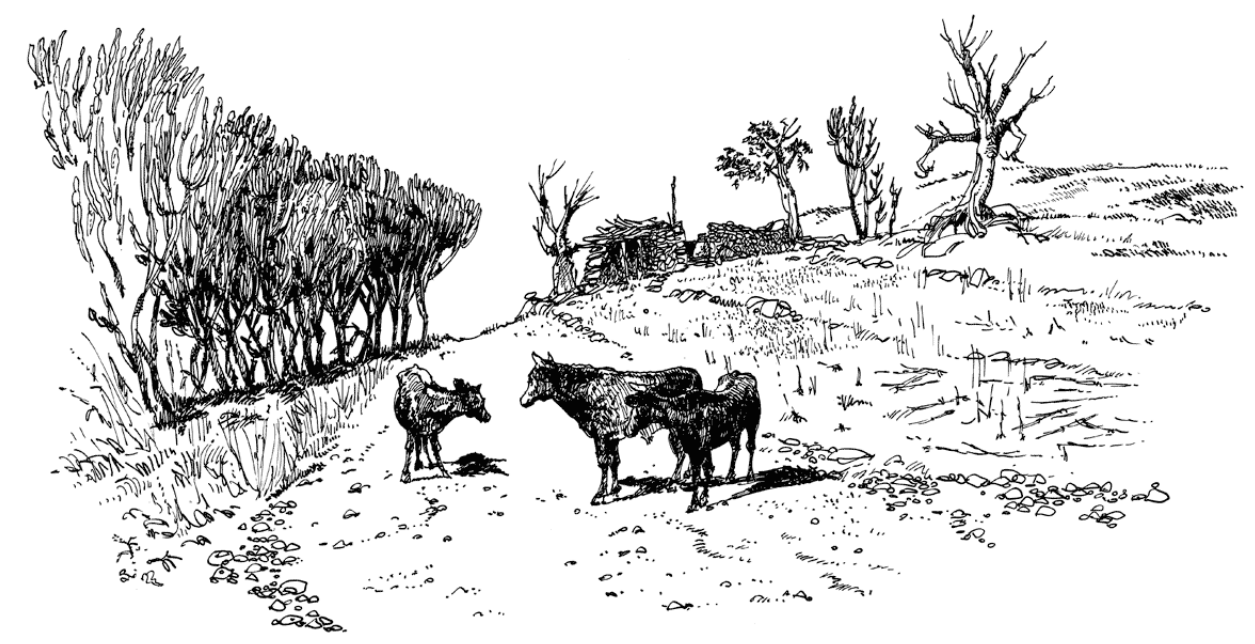

Les rapports entretenus par les sociétés montagnardes avec le taurin étaient différents de ceux avec le zébu de plaine, débarrassé, lui, d'une part de son humanité, même si on le " pleure » lors du sacrifice et que l'on en réfère aux ancêtres. L'élevage taurin reste lié à des structures aristo-gérontocratiques dont on décline différentes formes avec les Kapsiki et les Dowayo (Seignobos \& Thys 1998). La substitution du taurin par le zébu dans son mode « élevage claustré » correspond à une forme de démocratisation de l'élevage bovin.

Pour autant l'institution de la fête du maray a-t-elle vu le jour avec le changement de nature de l'animal sacrifié ? Il semble qu'il s'agisse d'un héritage économico-festif que les montagnards n'ont pas voulu abandonner, mais qu'ils ont adapté à leur nouvel environnement, les prestations rituelles évoluant progressivement aussi de leur côté.

Dans le parc arboré on remarque, à l'inverse, l'effacement de Celtis integrifolia. Chez les Mafa une sauce dite kwetefe (feuille de Celtis) se préparait encore au moment du sacrifice du maray à l'intention de ceux qui ne sacrifiaient pas de taureau. Il était licite de célébrer la fête du maray avec la plus grosse igname en fosse, qui représentait une valeur sociale équivalente. Néanmoins l'igname et la sauce de $\mathrm{Celtis}^{21}$ ne constituaient pas des sacrifices par défaut, pour remédier à un manque de bovin. À Ziver et à Soulédé, la volonté de certains quartiers ou plus exactement de clans marquaient par là le refus de cette nouveauté qu'aurait alors représenté le maray ou sa nouvelle ritualisation (fin $\mathrm{XVII}^{\mathrm{e}}$, début XVIII ${ }^{e}$ siècle ?). À la suite d'une "conversion" générale au rite du maray, ce clivage historique semble aujourd'hui difficilement reconstituable, le maray s'imposant peu à peu comme une fête centrale qui fédère tout un ensemble de groupes montagnards. 


\section{Les modes culinaires du temps de l'éleusine et des petits mils}

Une rotation culturale biennale contraint à des changements d'alimentation d'une année sur l'autre. L'une est consacrée à la boule de petit mil, l'autre à celle d'éleusine avec un appoint de sorgho, qui ne cessera de croître, et l'appui des incontournables niébés. Il semblerait que l'on mangeait beaucoup plus de bouillies de farine intégrant des fruits et aussi des boules de sycones de Ficus.

Nous avons évoqué le développement des cucurbitacées dans l'agrosystème et l'arrivée de Cucurbita pepo, énorme citrouille, qui marquèrent les esprits. Les cucurbitacées transforment significativement la diète annuelle des montagnards. Chaque cucurbitacée est susceptible de fournir des brèdes par ses jeunes feuilles, ses extrémités, ses inflorescences et ses graines. Toutes peuvent être consommées à l'état immature, y compris celles des calebasses (sloh wayam en mafa) cuites avec du sel de potasse. Enfin, les montagnards ont su intégrer les courges avec d'autres légumes antérieurs, multipliant ainsi les recettes.

4 Les brèdes sont issues de nombreux Ficus, du tamarinier (jeunes feuilles et fleurs) et aussi d'un "gombo sauvage ", Hibiscus asper, aux fruits à piquants qui aurait été cultivé dans certains massifs ${ }^{22}$, ainsi qu'une oseille sauvage. Nous avons observé en 1991 la reprise d'une culture ancienne de Ceratotheca sesamoides à Vouzad et à Magoumaz, effectuée sur des buttes circulaires très bombées. Ce Ceratotheca est cultivé pour ses graines, à la demande des maraîchers de Meskine, pour leurs planches de cultures de contresaison. Les semences doivent être régulièrement renouvelées, les feuilles perdant leur goût dans les espaces maraîchers. Jadis, chez les Mafa, elle constituait une véritable culture de légumes réservée aux fonds de talwegs humides.

Taurins et zébus donnent également leurs suifs, même si le gras est assuré au quotidien par le condiment huileux des graines d'oseille de Guinée de longue date incontournables en raison aussi de leur pouvoir de conservation, et encore par l'omniprésence de petites cucurbitacées oléifères. Dans la recherche de lipides on peut signaler la récupération des graines de cotonniers. À la différence des montagnards du nord, les groupes méridionaux, Gude, Jimi, Njegn, Fali ont développé à partir du XVIII ${ }^{\mathrm{e}}$ des jardins de cotonniers pérennes ${ }^{23}$.

Le sucre est plus que jamais obtenu par les fruits de jujubier, Ficus, Diospyros mespiliformis, Haematostaphis bartheri et surtout Vitex doniana. Chez les Gude comme chez les Jimi, à l'heure actuelle, dans ce périmètre des archaïsmes, on confectionne une mélasse avec la pulpe de fruits de Vitex, récoltés en octobre-novembre. Très souvent on force le fruit à mûrir dans le sol. On comprend mieux la figure de mythes, courante dans la région, où deux groupes qui s'opposent pour le pouvoir s'en remettent au sort, chaque parti enterrant un lot de fruits de Vitex. Lors du déterrement en public celui qui verra son lot mûr prendra le pouvoir. Naturellement un des deux partis triche et l'emporte ${ }^{24}$.

Chez les Jimi et les Gude, les fruits sont pilés sans toutefois toucher à leurs noyaux. Cette pâte est stockée et on en prélève des parties que l'on fait macérer avant de filtrer ce mélange pour des bouillies avec de la farine d'éleusine. Après un bouillissage plus ou moins long ce filtrat donne soit un sirop, soit une mélasse (madiya en gude) qui se conserve une année dans des poteries hermétiques. Cette mélasse sera incorporée dans des boulettes de farine de mil et le sirop mélangé à de la pâte de souchet pour en accentuer la saccharité. À l'arrière de chaque habitation jimi (à Bourrha Wamgo) et, dans 
une moindre mesure, chez les Bana, on trouve alors des monceaux de noyaux de Vitex. Ils seront à l'origine de macrorestes que l'on mettra au jour sur les sites de piémont, le long du mayo Tsanaga, chemin emprunté par une composante des peuplements jimi et bana. La découverte de noyaux de Vitex, comme à Mowo, est à mettre en connexion avec des plaques d'argile durcie ou des fosses remplies de restes de végétaux mélangés à de la cendre. Cela renforce « l'idée de cueillette, de transport et de consommation » du fruit du Vitex (Delneuf \& Otto 1995 : 220) pour le XIV ${ }^{\mathrm{e}} \mathrm{AD}$. Il en est de même, toujours sur les abords des Mandara, de Ceiba pentandra, de Bombax costatum et de Celtis integrifolia (Delneuf \& Medus 1997) présents dans les diagrammes polliniques des fouilles archéologiques.

Les boissons alcoolisées antérieurement au XVIII ${ }^{e}$ relèvent plutôt de bouillies alcoolisées consommées chaudes, principalement à usage cérémoniel. On y rajoutait de l'huile comme cela se pratique encore chez les Jimi et les Gude avec de nouveaux crus de bière. L'huile de cucurbitacée ou de sésame limitait l'acidité du breuvage et son brillant colorait la bouillie et conférait à la lèvre supérieure du buveur ce même brillant qui exprimait ainsi l'abondance et le bien-être.

La bière de petit mil ne semble pas avoir réellement existé, celle d'éleusine, en revanche, plus forte et plus sucrée, a compté deux breuvages, une bouillie et une autre plus liquide et claire. L'éleusine a, par la suite, servi à compléter le maltage des sorghos. Il existait des bières de seconde catégorie, des sortes d'ersatz, comme le cemcem chez les Mafa; on délayait dans l'eau des restes de boule de mil avant de rajouter de la farine grossière de grains de sorgho germés. Ici encore les bières de funérailles ont conservé d'antiques recettes avec, toujours chez les Mafa, le mandabe, bière servie chaude, ou encore, chez les Fali, le bueru fabriqué avec des grains de sorgho germés, grossièrement moulus, et mis à tremper dans de l'eau enfermés hermétiquement dans une poterie enterrée. Au moins six mois plus tard on l'exhume, on ajoute de l'eau et on le boit lors de funérailles.

On fabriquait des boissons alcoolisées extra cérémonielles surtout avec les fruits de Ficus sycomorus et de F. dicranostyla, et aussi plus anciennement encore? avec des baies de Syzygium guineense. Sur les piémonts on se procurait des «prunes» de Sclerocarya birrea dont on malaxait la pulpe pour les mettre à fermenter (Schnell $1957: 172$ ).

\section{Un agrosystème à tubercules dominants (antérieur au $\mathrm{X}^{\mathrm{e}}$ siècle)}

\section{Va-et-vient entre sauvage et cultivé ou les héritages de proto- agricultures}

101 Cette période intéresse des groupes humains paléo-Mofu, paléo-Mafa et autres, très différents des populations actuelles. Nous n'en conservons pas moins dans un anachronisme assumé les désignations des cultures et végétaux dans les langues actuelles. Plus on remonte dans le temps et plus les indices sont ténus. Imaginer un agrosystème non céréalier dans les monts Mandara est malaisé. Pourtant un certain nombre d'indices militent en faveur de cette hypothèse. Certaines Lamiaceae, les «Coleus »: Plectranthus esculentus cultivés sur deux ans et Solenostemon rotundifolius ${ }^{25}$ (Figure 15) furent généralisés dans le passé à une époque sensiblement plus humide. Les lamiaceae occupaient les fonds des talwegs, les cuvettes ou les ressauts de pentes, sur des billons aplatis exigeant peu de terre. Sur les pentes intercalaires les éleusines se semaient à la 
volée et les petits mils en poquets ${ }^{26}$, toutes cultures s'accommodant de sols pauvres et de fortes pentes. Les billons pouvaient être pérennes, pris dans de judicieux lacis de canaux où prospéraient les taros, comme on peut encore l'observer dans le parcellaire de WayZiver (Seignobos 1988).

Figure 15 : Lamiaceae

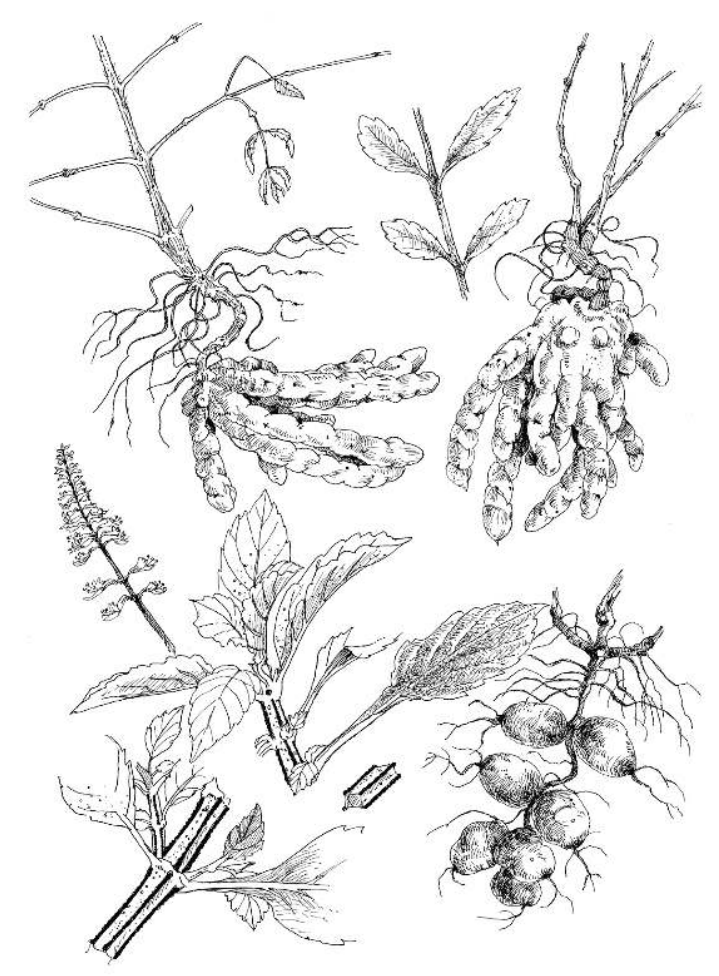

Bas, droite : Solenostemon rotundifolius. Haut, centre : Plectranthus esculentus. Haut, gauche : Vuhuna dla. Haut, droite : Vuhuna brenga

Plectranthus esculentus N.E. Brown (1894) a longtemps porté le taxon de Coleus dazo A. Chevalier (1904) ou celui de Coleus esculentus G. Taylor (1931). Au début des années 1980, j'ai envoyé à J. Miège (Genève) un matériel de Plectranthus esculentus des monts Mandara qui a pu être cultivé et étudié (Miège \& Moncousin, 1989).

Plante pérenne à port érigé Plectranthus présente des tiges herbacées devenant subligneuses en fin de végétation $(70$ à $90 \mathrm{~cm}$ ). Les feuilles opposées sont lancéolées, légèrement crénelées et pubescentes alors que les fleurs jaunes (14 à $18 \mathrm{~mm}$ ) se regroupent en panicules terminales. Les tubercules digités mesurent de 5 à $20 \mathrm{~cm}-\mathrm{j}$ 'ai pu en observer de $30 \mathrm{~cm}$ - pour un diamètre de 1,5 à $3 \mathrm{~cm}$. Chaque individu produit une griffe de huit à plusieurs dizaines de tubercules à chair blanche. À Boukoula, les Gude distinguent deux variétés: vuhuna dla dite "rampante», en fait aux tubercules se développant latéralement, et vuhuna brenga à chair couleur orange clair. Ces productions ont, depuis plusieurs générations effectué un repli des parcelles de plein champ où elles étaient cultivées sur billons vers des champs de case où elles sont produites à plat. À défaut de billon, Vuhuna brenga, plus massive, est confortée par un buttage.

Solenostemon rotundifolius (Poir) J.K. Morton (1962) a rendu caduques les taxons antérieurs, dont Coleus rotundifolius A. Chevalier et E. Perrot (1905) qui demeura longtemps la référence. Semi-pérenne, semi-crassulescente, plus ou moins rampante, branchue à la 
base, la plante offre des tiges remarquables quadrangulaires, aux angles saillants marqués d'une ligne rouge écarlate. Les feuilles de 3 à $8 \mathrm{~cm}$, opposées, épaisses, ovales, à nervure saillante sur la face interne, se colorent parfois de rouge. Deux à dix fleurs (5 à $7 \mathrm{~mm}$ ) surprennent par leur couleur bleu clair.

Les tubercules ovoïdes mesurent de 6 à $7 \mathrm{~cm}$ de longueur sur 2 à $2,5 \mathrm{~cm}$ de diamètre. La variété à peau foncée produit un tubercule de taille légèrement supérieure. La chair reste blanche. L'enveloppe de ce petit tubercule est repoussée d'une pression de la main. Plus répandu que Plectranthus, Solenostemon est partout cultivé sur des billons de 20 à $30 \mathrm{~cm}$ de hauteur.

Des témoignages de cet agrosystème ancien se retrouvaient au sud des monts Mandara chez les Fali de Bossoum et du Peské Bori encore dans les années 1970. Les cultures sur les pentes et les piémonts étaient réalisées grâce à la technique de billons longilignes très aplatis, larges de $40 \mathrm{~cm}$. Sur ces billons voués au complantage on cultivait des «Coleus » et, sur les bordures, des niébés ou, au centre, du voandzou ou du souchet avec toujours, sur les côtés, des niébés. Récemment encore les petits tubercules constituaient une alternative à la consommation des sorghos. Les Fali, au début $\mathrm{du} \mathrm{xx}^{\mathrm{e}}$, se réclamaient comme les plus gros producteurs de pois de terre au cœur même de sa zone de domestication. Cet agrosystème faisait ici encore la part belle à une cucurbitacée oléifère et aux vieilles variétés de sésame, rouges et noirs. Sesamum indicum représenta la grande plante oléifère du passé en concurrence avec les cucurbitacées oléifères. On le retrouvait encore en vastes champs sur les sols pauvres des monts Mandara durant le XIXe siècle. À l'arrivée de l'arachide il accuse un fort repli. L'alternance culturale : l'année de l'homme (sorghos) et celle de la femme (niébé, voandzou) durant quatre ou six ans, suivie d'une jachère sur le même pas de temps est encore pratiquée. La mise au jour de larges fers de houe pour la construction de billons laisse à penser que cette technique pouvait être plus largement répandue sur les abords des Mandara ${ }^{27}$. Ces fers à billonnage pouvaient être montés sur des manches coudés ou emmanchés droits comme une billonneuse du pays dii pour les ignames (Seignobos $1984: 554$ ).

107 C'est justement l'agrosystème de ces Dii (ou Duru), en zone soudanienne méridionale sous $1200 \mathrm{~mm}$ de pluie et à $300 \mathrm{~km}$ plus au sud, qui offrirait le plus de similitudes avec les civilisations agraires anciennes des Mandara. Au début du $\mathrm{Xx}^{\mathrm{e}}$ siècle, les Dii, arc-boutés sur les zones de repli sous la menace du lamidat peul de Rey, ont aménagé des terroirs dans les reliefs de la haute vallée de la Bénoué. On y cultivait Solenostemon rotondifolius et Plectranthus esculentus en planches intercalées entre des mils pénicillaires, beaucoup d'éleusines et des Sorghum guineense à cycle long, accompagnés d'une abondance de niébés. Les ignames sont très présentes, Dioscorea cayenensis, $D$. burkilliana, mais aussi $D$. abyssinica cultivée en fosse. Quant à D. dumetorum (hàà) appelée par les Dii «notre ancienne igname ", elle a fait ici l'objet d'une première domestication. Les semenceaux, prélevés sur des essarts et rapportés près des habitations subissaient un temps de «socialisation» avant d'être bouturés en champ, sur des billons (Seignobos 1998: 52). Chez les Dii, le système agraire ancien reposait sur les ignames, puis il a été recouvert, ici aussi, par un agrosystème céréalier de sorgho venu du nord-est. Mais à la différence des monts Mandara, le premier a continué à prospérer et les deux ont coexisté harmonieusement ${ }^{28}$.

Dans les monts Mandara ces Lamiaceae étaient cultivées en même temps que les ignames en fosse (Dioscorea abyssinica) que l'on conduisait en pérenne dans des emplacements creusés un peu comme des sols surcreusés d'étable pour le bétail claustré (comparaison 
utilisée par nos informateurs). On remplissait ces fosses de terre fumée et de vieilles pailles de toitures, le fond lui-même ayant été tapissé de tessons de poteries afin d'empêcher les tubercules de trop s'enfoncer en terre. On recherchait des arbres à proximité comme tuteurs ou on disposait un tuteur commun à la même fosse d'ignames. J'ai pu (1986) en identifier quelques-unes dans les Mandara nord, sur le massif de Moskota (Vrédéké) prises dans l'aménagement de terrasses et dégagées par l'érosion. On procédait aux récoltes tous les deux ou quatre ans selon les massifs ou, parfois, on prélevait chaque année une part de tubercule. Cette présence semble aujourd'hui la plus insolite. L'appellation de l'igname en fosse reste partout peu éloignée de sa racine tchadique ${ }^{29}$ bulom. Notons que chez les Mofu, les pierres dressées, sortes de mégalithes, autels voués aux ancêtres les plus éloignés, sont appelées mbolom. Chez les Mafa, les chefs de lignage les plus anciens, reconnus, inclus dans un clan (vazay) sont désignés par gad bulom (tête d'igname). Ce choix métaphorique curieux pour des céréaliculteurs renvoie au passé et permet de désigner les différents tubercules de la même igname comme autant de souslignages. 6ulom désigne aussi la poterie sacrificielle représentant l'esprit des ancêtres et placée sous le silo de l'aîné.

Le mouvement de va-et-vient de Dioscorea abyssinica entre les brousses et les habitations, des habitations aux champs, n'a pas fondamentalement transformé le «matériel » de brousse. D. abyssinica présente une spinescence peu développée. Toutefois en modifiant le comportement biologique du sauvage, le tubercule perd en longueur et en pilosité pour s'épaissir, la tête se réduit et, surtout, son amertume s'atténue. Les montagnards des Mandara, comme les Dii, prélevaient également en brousse des semenceaux de Dioscorea dumetorum qui se trouvent dans les éboulis rocheux proches. Cette Dioscorea réclamant peu de terre se cultivait sur des billons a minima. L'accroissement en volume des tubercules s'opère dans le sens latéral, aussi s'accommode-t-elle de sols peu profonds. Elle se dispense de tuteurage et, grâce à son port couvrant, freine l'érosion. Chez les Daba, les Gavar, les Fali... on rencontre dans les concessions des D. dumetorum en plantes de protection occulte. On observe une obligation d'héritage des têtes de ces tubercules par les aînés comme pour $D$. abyssinica. Cette très ancienne protoculture n'apparaît plus qu'en protection des greniers et des habitations, le tubercule étant fiché au sommet à l'aide de pics de bois (Seignobos 1994 : 8). Il n'est pas certain que la marche vers la domestication de $D$. dumetorum ait entrainé une perte totale de toxicité. Les montagnards disent avoir toujours pratiqué le rouissage dans l'eau des mayo du tubercule coupé en morceaux maintenus dans des fuseaux de graminées tressées, suivi du bouillissage de ces mêmes morceaux. Dioscorea bulbifera sauvage était ensemencée grâce à ses bulbilles chez les Mafa, Bana, Gude... dans des haies de Commiphora africana ou d'euphorbes appartenant généralement à des systèmes défensifs où elle s'auto-ensemençait par la suite. Le tubercule est consommé, mais très rarement les bulbilles. On le met à bouillir avant de le préparer.

110 On sait, depuis longtemps, que la cueillette assidue de plantes sauvages, même sur des siècles, ne suit pas forcément une évolution linéaire, conduisant à une domestication formelle. Certaines domestications n'aboutissent pas, d'autres connaissent abandons et reprises au gré de la contingence et du hasard. La mise en culture de matériels sauvages de Dioscorea a pu, au regard des modifications apportées au fonctionnement biologique de départ, se satisfaire de certaines étapes de domestication, pérennisant ainsi le phénomène. Le recul et l'abandon de la culture d'ignames dans les monts Mandara relèvent de causes multiples et combinées. On peut incriminer un amenuisement des 
pluies sur le long terme, la pénibilité de devoir réalimenter constamment le stock cultivé en semenceaux sauvages et le suivi de leur "domestication». L'obligation d'aller prospecter les gisements en plaine va connaître un arrêt, les piémonts mêmes devenant un milieu de plus en plus insécure pour les montagnards et, enfin, à cause de la difficulté de stockage.

Pour A. Chevalier (1949 B : 612) le prélèvement des ignames en brousse aurait constitué une des principales ressources des «peuples africains » avant l'invention de l'agriculture. La collecte régulière de ces Dioscorea sauvages pour les bouturer près des habitations aurait amorcé des formes de domestication. La culture des céréales supplantant celle des tubercules, une partie de ces derniers redeviendra sauvage. On ne saurait mieux l'appliquer aux ignames des monts Mandara.

112 Le taro (Colocasia antiquorum) devait déjà occuper les zones les plus humides des talwegs. Les Mafa distinguent encore deux variétés de Colocasia: mesler matarah (blanc) et mesler madzaha (brun noir), ce dernier étant le plus productif. Ces taros parviennent à maturité entre trois et six mois. Ce petit taro à chair blanche, de consistance glaireuse, présente un tubercule principal de $6 \mathrm{~cm}$ de diamètre, accompagné de tubercules secondaires peu nombreux, que l'on prélève une à deux fois dans l'année. Le tubercule principal reste en terre pendant cinq à six ans et reçoit chaque année un léger buttage. Des taros peuvent être déplacés des tarodières ou des drains-canaux vers les habitations au début du mois de juin afin de renforcer le lot de productions de soudure. L'habitude de déplacer encore des cultures, comme les pieds de taro ou des plantes de la flore spontanée comme Dioscorea spp., Ensete gilletii (Figure 16), Burnatia enneandra, Anchomanes welwischii, Tacca leontopetaloides (en plaine)... près des habitations afin de compléter son garde-manger, accrédite la vieille idée de quelques héritages de formes de protoculture (Schnell 1957 : 132). 


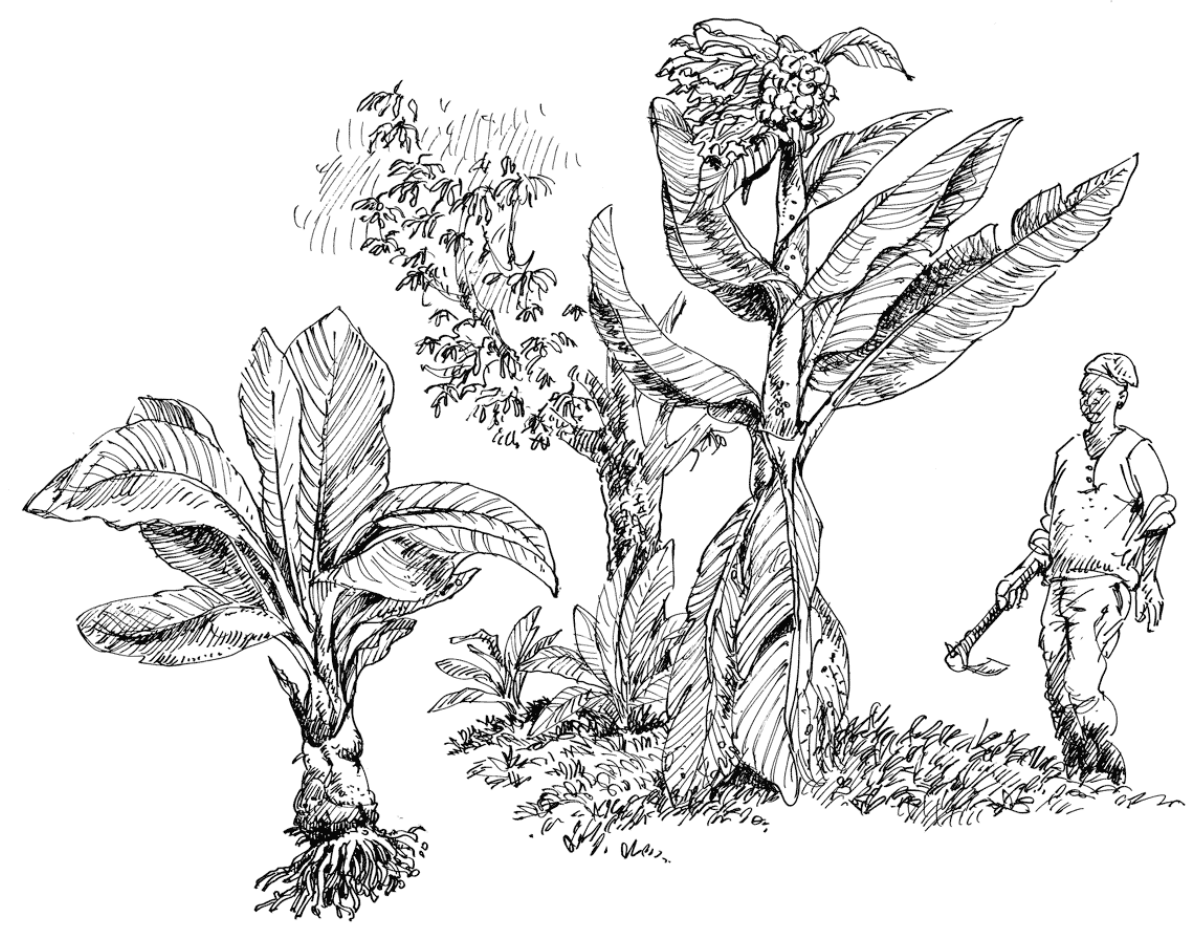

La production de grains était-elle alors confiée aux seules éleusines et aux petits mils? Et dans quelles proportions? Dans des sources désespérément silencieuses, nous ne disposons que de traces à découvrir souvent dans le complexe contes, mythes et autres récits sortis d'un passé immémorial. Parmi les nombreuses versions du conte/mythe sur le chien qui apporte le petit mil à l'homme, peu s'embarrassent de signaler les cultures antérieures. Le corpus mafa dont je dispose en présente deux. L'une a été relevée auprès de Surey Sakwan à Magoumaz: "Le chien vivait avec le singe. Il cultivait à l'aide d'un morceau de poterie alors que le singe grappillait des fruits et dérangeait sans cesse le chien en lui dérobant ses pois de terre dans le sol. Dieu le prit en pitié et lui prodigua ce conseil : « laisse le singe, ce voleur impénitent, va rejoindre l'homme, qui cultive comme toi, et pour l'amadouer fais lui un cadeau, apporte lui des grains de petit mil ». Depuis ce temps le chien reste chez l'homme et garde sa maison. Pour cela il reçoit chaque jour sa pitance ».

114 L'autre est de Bourtaye Giyeke, de Gouzda : «Le chien et le crapaud vivaient ensemble dans l'habitation (gay) de l'homme. Le chien s'abritait sous le grenier (shoekwetev) ${ }^{30}$ à éleusine (mbortak), alors que le crapaud restait dans l'eau de la pierre creuse - abreuvoir (torokw). En ce temps il n'y avait ni mil, ni feu. Le crapaud, lui, vivait à l'aise ayant à sa disposition des myriades d'insectes pendant que le chien souffrait de froid et de faim. Comme le chien avait quelques accointances avec Dieu, il partit au ciel et en rapporta le petit mil (mətəmas/n'tomas), mais croquer le petit mil cru était encore de la souffrance. Il repartit alors au ciel voler le feu et lorsqu'il revint, le crapaud prit peur et s'enfuit en brousse. Pour tous ces bienfaits, l'homme ne peut, sans raison, frapper un chien. Sa malédiction à l'encontre des hommes conduirait à un arrêt des pluies et à une fuite du mil ». D'autres versions du mythe disent que de son passage au ciel, le chien aurait rapporté le feu accroché à sa queue grâce à un épi de mil pénicillaire enflammé31. 
Dans ces deux contes, deux cultures se présenteraient comme antérieures au petit mil: les pois de terre et l'éleusine. L'apport du feu, métaphore ancienne, y compris dans les monts Mandara, désigne l'arrivée d'une aire civilisationnelle nouvelle auprès de populations qui, forcément, en étaient dépourvues. En général, nos informateurs situent bien une aire antérieure aux sorghos qui concernait le mil pénicillaire, sans toutefois pouvoir la préciser, alors que l'origine proche ou lointaine pour les sorghos est souvent désignée. Rappelons que le sorgho apparait, lui, comme volé par l'homme, les grains cachés dans son prépuce ou dans ses cheveux et ce dans une plaine dénommée «Wandala» (cf tous les mythes qui touchent aux clans du pouvoir à Mowo-Medey, (Vincent 1991 : 750). Ils hésitent à établir un démarquage dans le temps pour l'arrivée de l'éleusine et pour celle du petit mil. Il s'agit d'un tout, d'une forme d'horizon indépassable dans la remontée chronologique quant à leurs cultures et leur alimentation. Ils rattachent également dans cet "en deçà » les tubercules et les pois de terre. C'était pour eux le temps dit «des petites graines", le petit mil (Figure 17) (Pennisetum glaucum) ancien ressemblant au muuri (fflde), moro en kanuri, un écotype à petits grains qui a quasiment disparu de la plaine en raison de sa sensibilité aux oiseaux, mais aussi les premiers sésames rouges et noirs, Sesamum radiatum, le " sésame noir » et/ou Sesamum indicum (?), un Sesamum hyptis (mangwas gabam: femelle/sésame) des Mofu, une labiée qui a fourni des graines oléifères et, enfin et surtout, des éleusines. L'éleusine «c'est pour les gens d'avant » affirment les montagnards, autrement dit antérieur aux entités actuelles, Mofu, Mafa, Matal...Cette céréale de moins d'un mètre, à la panicule subdivisée en épillets de 7 à $8 \mathrm{~cm}$ dont le plus bas demeure toujours individualisé, a pu présenter de nombreux morphotypes déclinant épillets en forme ouverte, en coupe, en poings, avec différentes couleurs de graines ${ }^{32}$. Peu à peu ces variétés ont, en dépit de cycles variés, gagné un fond indifférencié d'éleusines. En 1970 Eleusine coracana race plana (Figure 17) et sans doute E. coracana r. coracana à grains rouges et noirs étaient encore identifiables (Seignobos 2002 : 104). Elles étaient jadis cultivées entre les planches de Lamiaceae et/ou en rangs alternés avec de l'oseille de Guinée ou simplement sur les pentes, adaptées qu'elles semblaient être à tous les sols. L'éleusine comme du reste le sésame en semis denses limitent la venue d'adventices et ne réclament qu'un sarclage expéditif. Les informateurs signalent de plus que ces productions réagissent bien à l'irrégularité des pluies. Ces cultures, Dioscoreaceae et Lamiaceae comprises, de par leurs ports naturels et les façons culturales dont elles firent l'objet, protégeaient de l'érosion. Par leur cohérence d'ensemble ces cultivars ont fait systèmes jusqu'à l'époque de la mise en place des terrasses, du moins celles de leur généralisation en gradins resserrés au service de céréales. 

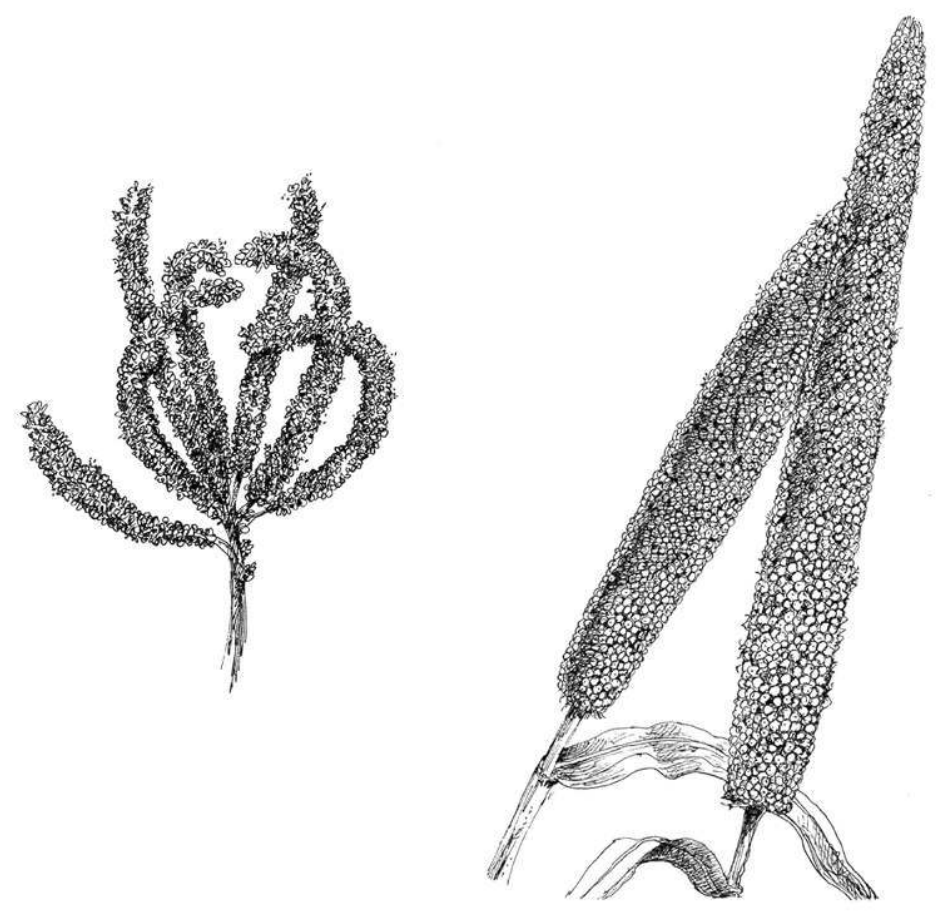

S'il faut apporter foi à Léon l'Africain dans sa mention du royaume du Borno et de la montagne qui ne peut être que les monts Mandara, au début du Xvi ${ }^{\mathrm{e}}$ siècle, il s'agissait déjà de populations possédant des céréales. "La montagne est peuplée de bergers qui gardent des chèvres et des bœufs. On y sème aussi du mil et quelques autres céréales qui nous sont inconnues » in La description de l'Afrique, Léon l'Africain (1956 : 104).

117 Pour autant éleusine et petit mil ont-ils amorcé les premières formes de rotation biennale ? Cette rotation a-t-elle été initiée sur les montagnes ou a-t-elle été héritée de populations de plaines? Et si cet agrosystème éleusine/mil pénicillaire et oseille de Guinée, voandzou, tubercules et niébés était au service de stratégies antiacridiennes ? Les vols récurrents de sauteriaux auraient-ils été plus fréquents dans le passé ou alors, dans les imaginaires collectifs, la menace acridienne serait-elle devenue démesurée ? Auraientils alors freiné le développement des sorghos, que l'on sait particulièrement vulnérables jusqu'à la maturité des panicules ? Lors de la "grande famine des criquets » (1930-1936), certains groupes montagnards comme les Mada ont opéré une reconversion vers une monoculture d'éleusine en deux ans (Seignobos 2000: 111). On peut par ailleurs réimaginer les jardins de cases avec des petits mils hâtifs et les tout premiers sorghos ${ }^{33}$.

Une culture semble s'imposer par son anciennetée ${ }^{34}$, son adaptation au milieu et sa prégnance dans l'agrosystème : les niébés (Vigna unguiculata). Chez les Mada, Matal, Mafa, Kapsiki et Gude, cette région d'échines montagneuses réunit le plus grand nombre de niébés anciens appartenant au cultigroupe Biflora. On compte une douzaine de cultivars et des formes de transition, commensaux véhiculés par l'homme jusque dans ces refuges montagneux ${ }^{35}$. Les Mafa se présentent, dans ce domaine, comme le groupe montagnard le plus conservateur et les seuls à faire un abondant usage de cultivars à "phénotype sauvage». Autour d'eux, depuis les Kirdi Mora jusqu'aux Kapsiki, les niébés du 
cultigroupe Biflora à graines colorées dominent. Ils sont ensuite pris dans une auréole, à la périphérie des monts Mandara, qui concerne le cultigroupe Melanophthalmus, graines blanches avec différents types d'œil et téguments lisses (Pasquet \& Fotso 2000 : 90).

Les phénotypes qui ont gardé les «types sauvages " présentent des colorations grises, marbrées, tachetées renforçant le camouflage de la graine avec parfois aussi des comportements semi-déhiscents. Chez les Vigna unguiculata C.G. textilis, les plus anciens niébés, les grains même déhiscents sont consommés.

Nous avons suggéré que, dans les rotations précédentes, les termes forts de l'alternance étaient constitués une année par les céréales, suivie de légumineuses dominées par les niébés. Pour R. Pasquet (2000: 88), l'importance des niébés dans l'alimentation du montagnard et partant son impératif de culture, contraint pour des causes sanitaires à une pause une année sur deux. Ainsi le niébé, promu nourriture salvatrice, aurait pu, à un moment donné, imposer une rotation proprement montagnarde.

121 À côté de ces niébés, une autre légumineuse, le pois de terre (Voandzeia subterranea), dut connaître à cette époque une mise en culture plus importante. À la différence des niébés, les pois de terre ne présentent pas de régions à phénotypes dominants, ce qui suggère pour cette plante fortement autogame une circulation très ancienne des semences ${ }^{36}$. Dans les Mandara, le pois voandzou est dit celui de l'homme (l'autochtone) par rapport à l'arachide, apparue tardivement. Chez chaque groupe montagnard on rencontre les mêmes types: un gros rouge, le plus ancien, à cycle long, mavaray, celui de Mowo ; un petit rouge, à gousse fine ; un tacheté du nom d'un oiseau à plumage de la même couleur ; un blanc, petit, et récemment enfin : un gros blanc. Cultivé par variété ou plutôt selon les cycles, sur de petites parcelles, et encadré par du sésame et de l'oseille de Guinée, le pois de terre permet des récoltes différées car il peut rester en terre sans dommages. Aussi endosse-t-il, depuis longtemps, le rôle d'aliment de soudure.

Le souchet (Cyperus esculentus), que les services d'agriculture s'obstinent, depuis l'époque coloniale, à appeler « chiendent » au vu de son aspect extérieur, offre cinq à six cultivars dans les monts Mandara. Le semis du souchet intervient en août, sur des billons plats où a été préalablement épandue de la cendre. La récolte se réalise par arrachage pour les variétés à petits tubercules et à la houe pour celles à plus gros tubercules. On trouve des échappés de culture dans les milieux perturbés et, pour les populations montagnardes, des sauvages qui reçoivent d'ailleurs une appellation distincte. Chez les Kapsiki de Gouriya, le cultivé est dit lakə et le «sauvage » dovə. Le souchet cultivé est appelé mənda chez les Mafa, gwejene, le souchet de repousse alors que manda tugwam (= souchet/grand calao), serait le sauvage, différent de Cyperus termiculmis, manda wayam (souchet/ ruisseau). Au cours de ce dernier millénaire cette culture très ancienne a enchaîné des pulsions d'exploitation et de délaissement.

On serait en présence, comme pour les niébés, si bien étudiés par R. Pasquet (Pasquet \& Fotso 1991), de semi-sauvages qu'il nomme "sauvageoïdes ». Cyperus esculentus fournirait plus abondamment encore ce type de plantes férales ou de «sauvageoïdes» dans les Mandara méridionaux.

Dans cet agrosystème issu de civilisations agraires "premières" on pressent la multiplication de gestes de proto-agriculteurs. Les ignames en fosse en illustreraient l'héritage le plus direct. 


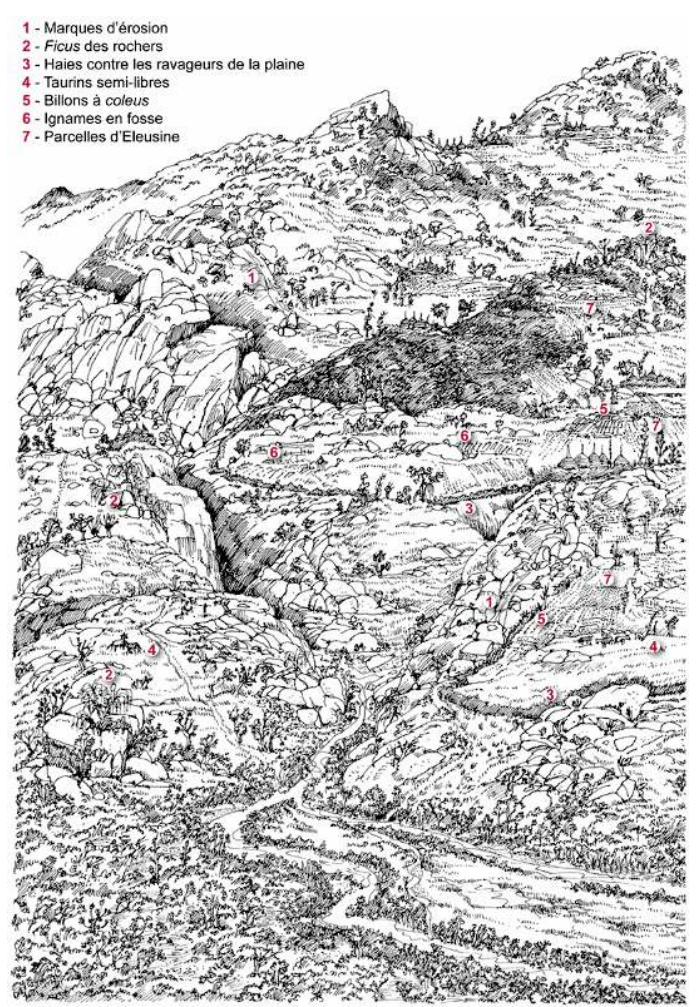

Reconstituer le parc arboré de ces périodes reculées stimule certes l'imagination, mais apporte peu de certitudes. Les arbres reliques de paléo-environnements pouvaient être plus nombreux. Ils se présentent aujourd'hui comme des végétations d'altitude : palmiers nains, Phoenix reclinata ou encore Croton zambesicus du mont Ziver, Olea hochstetteri sur le sommet d'Oupay (Letouzey 1968). Seul Antiaris africana (Figure 19) (marawaz) exclusivement présent aujourd'hui en pays mada (Seignobos 1997) reste très sollicité pour ses brèdes. Sa taille, si particulière, en peupliers d'Italie est unique dans les monts Mandara. Les précautions rituelles qui entourent la cueillette des brèdes et la perplexité des populations devant la reproduction de cette essence, en font une authentique relique. Il s'agit de relictes (?) abandonnées au cours d'un « repli » vers le sud de ses congénères sauvés ici par une sur-anthropisation. Les Celtis integrifolia peuvent parfois aussi se présenter traités en peuplier d'Italie, toujours dans la région mada-matal. L'arbre a pu fournir une production oléifère et de brèdes conséquente dans le passé ${ }^{37}$. On ne recense aujourd'hui que de vieux spécimens. Celtis integrifolia, Grewia spp. et Vitex spp. composent une trilogie de sources alimentaires qui fut autrefois particulièrement présente dans la bande sahélienne, ce dont rendent compte la plupart des grands chantiers de fouilles (Tourte 2005, vol.1: 25, 27). 


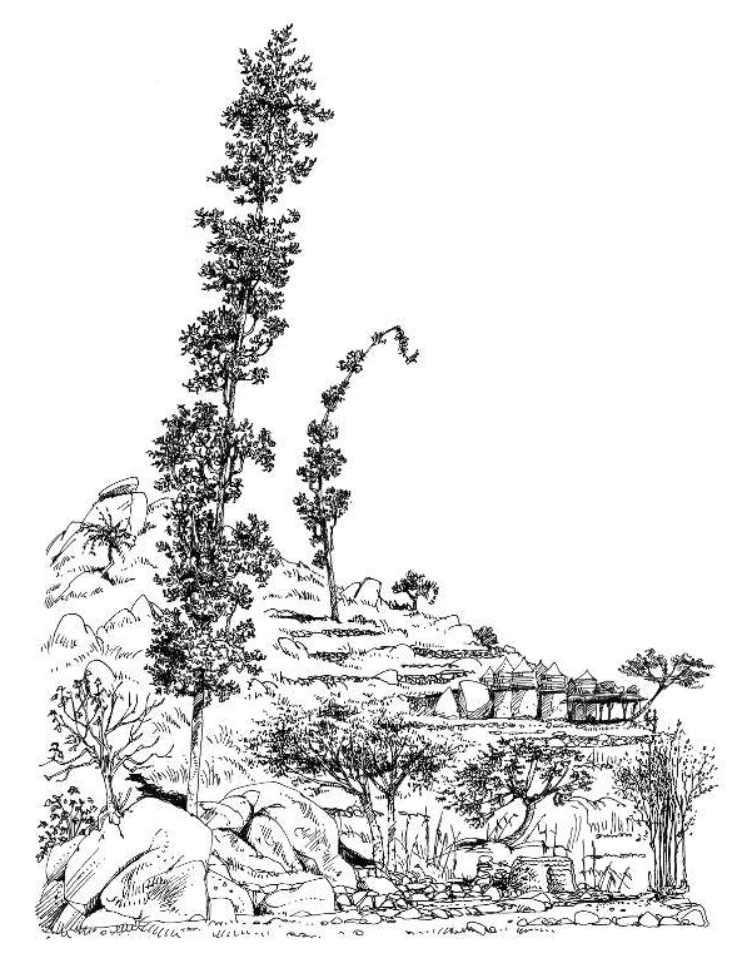

Dans les monts Mandara, les arbres nourriciers les plus anciennement reconnus sont les Ficus. Ficus abutilifolia est une essence des rochers remarquable par son système aérien très développé. Semé dans les fentes et les diaclases des rochers en compagnie de F.umbellata et $F$. cordata, haut de 10 à $15 \mathrm{~m}, F$. abutilifolia porte une génération de fruits par an dispersés par grappes au-dessous des feuilles, de juin à août. Il fournit un fourrage à un moment où la montagne en est dépourvue. Couper ce Ficus constitue un délit majeur. Chez plusieurs groupes montagnards la discipline concernant la protection de $F$. abutilifolia (vol de feuillage, liber, bois...) est indexée sur la vie des enfants du « coupable ». Ficus dicranostyla (mindek) pourrait avoir fait l'objet d'une diffusion ancienne. On le rencontre, sous les murets des terrasses, taillé pour rester arbuste sur une base tortueuse à gros diamètre chez les Mafa nord (Dury 1991). Il peut néanmoins devenir un grand arbre de $20 \mathrm{~m}$, près des habitations et se voir aménagé avec des échelles pour favoriser l'accès aux branches toute l'année et pour éviter le contact avec sa sève urticante. Nous l'avons trouvé dominant dans les parcs de certains quartiers mafa, mboku et molkwo. On rencontre d'autres Ficus dans les talwegs près des ruisseaux, comme Ficus sycomorus, dont on consomme jeunes feuilles et sycones. Il en va de même pour Ficus glumosa: les fruits abondants, plusieurs cueillettes sur toute l'année, servent à préparer des boules de disette. Ficus platyphylla souvent épiphyte à l'origine, se bouture facilement. Toutefois son fort développement le cantonne plutôt dans les piémonts. Il permet deux cueillettes (saison sèche et saison des pluies) d'innombrables tout petits sycones. Ses jeunes feuilles sont également mises à contribution. Dans les monts Mandara méridionaux, les Ficus déjà signalés sont moins représentés, mais en revanche Ficus thonningii d'introduction plus récente fournit encore jeunes feuilles et fruits sucrés pour des bouillies de farine de mil. 
Ziziphus mauritiana fait cortège aux Ficus comme arbre d'utilisation immémoriale. Arbre de cueillette privilégié grâce à ses jujubes, il illustre à lui seul cette proto-arboriculture qui dut précéder les balbutiements de la culture céréalière (Chevalier 1947). Dans les monts Mandara où, très tôt protégé voire semé, il s'affiche partout dominant dans le parc arboré de chaque massif.

\section{Aux origines des modes culinaires des peuples des Mandara}

Beaucoup de questions demeurent sans réponse : comment consommait-on au quotidien les petits tubercules et les ignames en fosse. Les sauces qui les accompagnaient étaientelles les mêmes que celles associées aux céréales? Tous dégageaient peu ou prou une légère amertume qu'il fallait dissiper. Pour les ignames en fosse, par exemple, on les faisait cuire une première fois pour enlever la peau avant de les préparer avec du sel de potasse.

On peut néanmoins postuler un rôle ancien dévolu aux niébés et aux pois de terre. Si les niébés sont les plus anciens et les plus développés dans les Mandara plus que partout ailleurs, la raison serait à rechercher dans le manque de protéines concurrentes. Sur la montagne il n'y a - y en a-t-il jamais eu ? - ni poissons, ni batraciens, la viande de chasse était rare et l'élevage, contraint par un fort contrôle social, connut un développement modéré. Avec la densification du peuplement, qui réduisait les zones de cueillette et limitait les parcours du bétail, le besoin en niébés n'a fait qu'augmenter. Dès lors on assigne aux niébés une place éminente autant dans le système de production que dans l'alimentation des hommes et des petits ruminants.

Leur culture sur des cycles bisannuels, leur consommation l'année de la femme, contraignait à une forme de cure de niébés. L'année suivante on ne dégageait que peu de niébés ayant réussi à échapper aux bruches (Callosobruchus maculatus) et on devait même cultiver un peu de niébé à usage semencier exclusif. Au moment de la récolte on consomme des niébés en plat unique quasi quotidiennement dans certains massifs et plus généralement trois à quatre fois par semaine. La cuisson est toujours longue, deux heures, à l'exception des niébés plus récents, Cultigroupe Melanophthalmus aux téguments plus fins, ils reçoivent toujours un assaisonnement de sel de potasse. Ils peuvent être cuits avec des sorghos et des mils en grains (daw-maras, mil-niébé sec cuit, en mafa) ou en pâte comme pour le pois de terre. Mais avant cette étape on a consommé les jeunes feuilles ( $z b a k$, mafa) durant un mois complet et dans toutes les sauces ${ }^{38}$. On peut également cuisiner les gousses immatures. Plus de la moitié des sauces dans les monts Mandara septentrionaux intéressent les niébés.

Les niébés constituent à eux seuls une sorte de complexe culinaire : feuilles fraîches ou séchées, eau de bouillissage de certaines graines récupérée et lixiviée en sel de cendre, jus-condiment (tsatsaw en mafa) à partir de phénotypes de formes sauvages macérés dans des pots hermétiquement fermés... Chaque groupe présente des onomatopées censées reproduire le bruit des aliments pendant leur cuisson. Les plus courantes, et de loin, intéressent la cuisson des niébés et, secondairement, celle des courges. Nos informateurs insistent sur l'ancienneté de ces préparations avec sans doute l'idée de perpétuer à l'identique "la nourriture des ancêtres ». Certaines sauces étaient proprement dédiées aux niébés, mais une infinité d'autres pouvaient intégrer des graines de niébée ${ }^{39}$ : toutes les "sauces vertes", feuilles de mindek, de Ceratotheca sesamoides, de Corchorus spp.... Seules les sauces avec sésame ou arachide (makawatab en mofu) en seraient dispensées, 
de même que les "sauces longues", lar sekwer, à base d'aubiers de Grewia spp. Cette surabondance du niébé dans l'alimentation présenterait une constante dans le temps quelle que soit la céréale dominante sur la montagne. Elle est toujours perçue comme un trait dominant de la cuisine des montagnes.

Les montagnards peuvent difficilement imaginer leur alimentation aujourd'hui à base de farine, sans sorgho, mais plus encore sans niébés. Chaque fois que nous avons partagé des repas de niébés, dont les grains étaient tellement attaqués par les bruches que l'on avait peine à reconnaitre le haricot..., simplement assaisonnés de sel de potasse, et présentés sur le plat de bois traditionnel, nos hôtes précisaient que c'était là « une nourriture d'avant d'avant ».

Quant aux Ficus (Figure 20) nourriciers, le plus exploité, Ficus dicranostyla, offre ses jeunes feuilles, premières brèdes au mois de mai, avant les pluies, consommées quotidiennement jusqu'au relais des feuilles de niébés. Ensuite séchées ces feuilles entrent dans des recettes de sauces en accompagnement de bien d'autres légumes. Certains informateurs signalent des départs de jeunes feuilles hors saison. On observe souvent plusieurs générations de fruits de couleur jaune-rouge ou carrément sanguine, au cours de l'année: aoûtseptembre, décembre-janvier et, parfois, mars-avril. Ces sycones sont consommés verts, mûrs, séchés, bouillis, pilés en boule. Le liber de $F$. dicranostyla sert d'exhausteur de goût pour de nombreux mets et parmi plusieurs communautés. Par exemple, chez les Kapsiki, il est introduit dans la pâte de sésame ou d'arachide et reste ainsi pendant plusieurs jours. Une fois débarrassée du liber la pâte a acquis un goût incomparable.

Figure 20 : Ficus

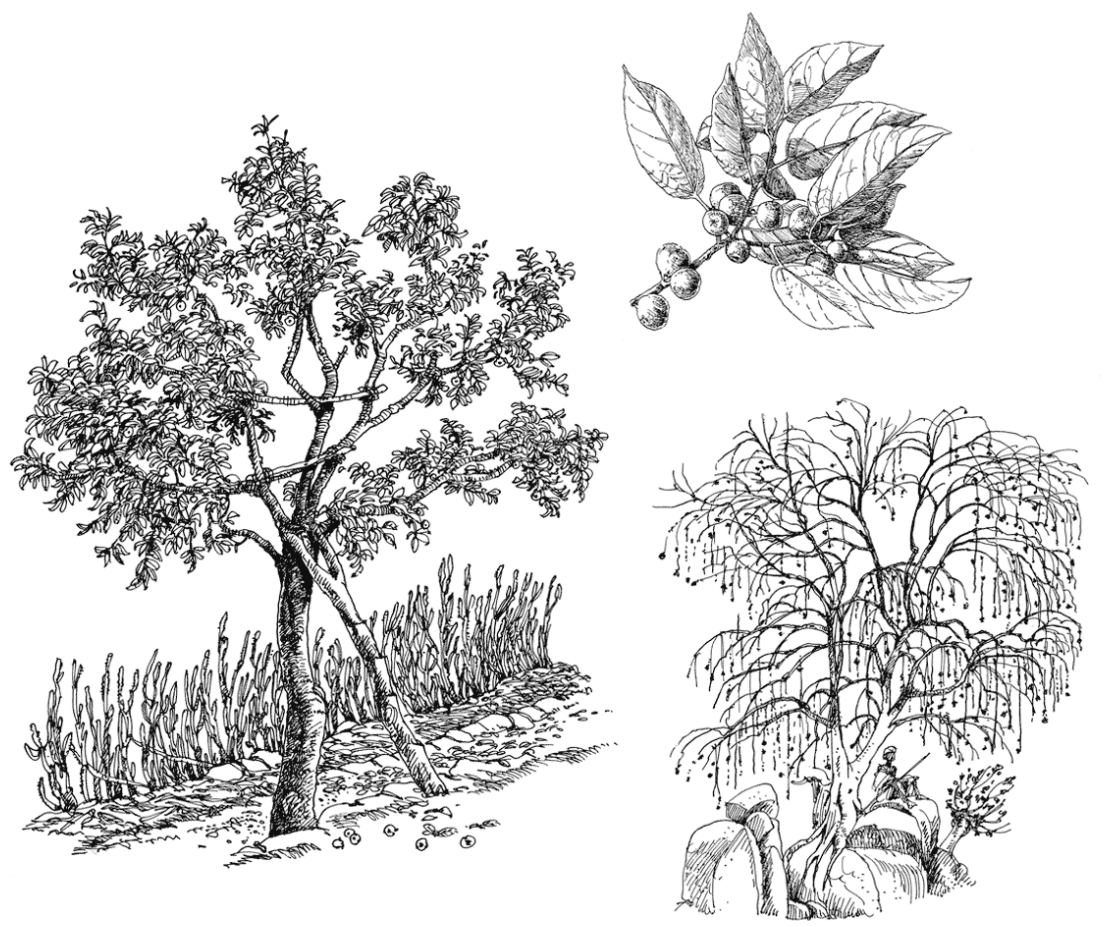

Gauche : Ficus dicranostyla, Boukoula, monts Mandara centraux. Haut : Fruits de Ficus dicranostyla. Droite : Ficus abutilifolia 

anciennes de la montagne. plus communes.

\section{Conclusion}

Les larges feuilles, presque rondes $(18 / 19 \mathrm{~cm})$, de $F$. abutilifolia, considérées comme particulièrement saines et sans odeur, enveloppent la pâte de niébés en petits paquets, pour une cuisson à l'étouffée. Son aubier pilé et cuit comme un légume entre dans la préparation de viande de chien ou de gibier. Son bouillon acquiert avec l'adjonction de sel de potasse un goût sucré salé, rappelant quelques sauces asiatiques un peu fades. Son bois est macéré pour des sauces au sésame ; adultes et enfants mâchent son liber à la fois sucré et rafraîchissant. On peut, à partir des Ficus, reconstituer les recettes de cuisine les plus

36 Le taro rappelle aussi son ancienneté par son association à d'antiques recettes à base de Ficus. Toutes les préparations de taro visent à limiter l'effet irritant pour la gorge des raphides d'oxalate de calcium; on le cuit après bouillissage sur un fond de feuilles écrasées de Ficus dicranostyla. Les jeunes feuilles de taro sont également additionnées d'aubier de Ficus pour la cuisson.

La concurrence entre brèdes sauvages et légumes cultivés a commencé très tardivement chez les montagnards au contraire des cultivateurs de plaine. Le relevé de contes anciens dans les monts Mandara évoque souvent l'intervention d'une jeune fille qui va cueillir des feuilles nouvelles et des fleurs de tamarinier pour la sauce et, à cette occasion, elle fait une rencontre... mais il existait tant d'autres essences à légumes-feuilles.

Parmi les besoins alimentaires exprimés, c'est toujours et encore la graisse qui relève de l'essentiel et on la recherchait partout... et naturellement avec la graisse animale et le sang mis à pourrir dans le péritoine des petits ruminants avec de la pâte de sésame (ndel luweng en mafa) et ensuite à sécher.

Le sucre, en dehors du souchet déjà présent, ne pouvait provenir que de fruits: Vitex doniana, Diospyros mespiliformis, Haematostaphis bartheri, Syzygium guineense, Annona senegalensis encore en peuplement pur sur le sommet de Oupay, mais aussi de liber de Ficus. S'ajoutait aussi l'exploitation de ce vieux «complexe de plantes » occupant les mêmes milieux, à l'ombre d'essences arborées tutrices. Parmi elles : Grewia spp., Capparis corymbosa pour leurs fruits et aussi Cadaba farinosa. Ziziphus mauritiana, lui, a joué depuis des temps fort anciens un rôle dépassant la production d'aliment sucré. Les jujubes, systématiquement récoltés, mis à sécher, puis stockés dans des compartiments de silo voire des silos entiers restaient sous le contrôle exclusif du chef de famille. On consommait des jujubes sous forme de bouillies de farine mélangée à celle d'éleusine ou de petit mil composant même une des «farines à boire " parmi les plus anciennes et les

40 La cueillette de brèdes et de libers comme exclusivités légumières et un certain nombre de cultures : niébé, pois de terre, souchet, semblent avoir transcendé la succession des systèmes agraires et ont pu partant remplir le même office dans les pratiques culinaires.

41 Les montagnards des Mandara ont, par ailleurs, partagé un certain nombre de constantes alimentaires avec les populations des plaines : sels de potasse, cynophagie, entomophagie et autres aliments de famines que nous n'avons pas abordés ici.

Dans la succession des agrosystèmes et l'intrusion des nouvelles cultures qui ont participé à leur transformation. Il s'agit bien, répétons-le, non pas de diffusion de cultivars, mais du 
redéploiement, à travers de nouvelles combinaisons culturales, de plantes alimentaires connues souvent depuis fort longtemps par les intéressés.

Sur la base de la reconstitution d'une évolution possible, sinon probable, des agrosystèmes à partir d'un état des lieux (1930) encore directement observable dans nos enquêtes, nous avons tenté de remonter le temps.

Pour ce faire, et dans une démarche pour le coup heuristique, on s'est appuyé sur quelques éruditions discursives mentionnées dans l'introduction et sur le regard que portaient un grand nombre de vieux informateurs - qui le furent souvent pour moi à propos d'autres sujets - sur les générations qui les avaient précédés, nourris aussi à leur propre imaginaire. Nous avons engagé bien des questionnements à partir de plats «à l'ancienne " consommés de façon impromptue ou à partir de commandes auprès de vieilles femmes lors de différents séjours de terrain.

Nous avons regroupé nos observations sur les agrosystèmes et leurs corrélats culinaires en trois grands tableaux dont on ne peut occulter l'arbitraire. Nous avons construit cette succession sur des marques d'antériorités comparées, l'analyse rétroactive s'appuyant souvent sur les ultimes observations de l'expression du passé.

Les monts Mandara ont suivi la même évolution d'ensemble des protocultures hésitantes des débuts vers des systèmes toujours plus intensifs. Toutefois les milieux montagnards ont manifesté une grande indépendance par rapport à ce qui se déroulait en plaine. Ils sont restés des espaces conservateurs contenant, pendant longtemps, les sorghos en plaine, se contentant de "céréales pauvres" (éleusines et mils) adaptées à un milieu édaphique indigent. Ainsi se sont maintenues des pratiques agricoles et des cultivars ou des élevages singuliers ailleurs disparus. Aussi, pour reprendre le schéma d'une évolution linéaire et formelle, le passage des "végéculteurs " (plantes à reproduction végétative avec Disocorea et "Coleus») à celui de "graniculteurs" (Tourte 2005, vol.1: 89-90) interviendrait, pour les monts Mandara, à une période plus récente et sur un pas de temps sans doute plus long. Il s'achèverait au moment où les "gens des rochers" maîtrisent leur environnement ou plutôt le créent en modelant des terrasses et en pratiquant un contrôle actif de l'eau dans les zones fragiles des talwegs. Sous la contrainte, le montagnard a dû adopter un comportement plus volontariste, qui trouve son aboutissement dans les panels de cultures adaptées à son milieu minéral. La révolution des zlaraway, ces sorghos inféodés aux seules arènes des terrasses que l'homme a créées pour sa venue, magnifiera sa réussite. Toutefois cette passion exclusive portée aux sorghos ne peut se satisfaire des seules stratégies d'aménagement de l'espace, elle ne sera effective que grâce à une plante nourricière d'exception, mais également élément clé des combinaisons agraires : le niébé. Sans lui la céréaliculture de montagne n'aurait pu exister. Ce sera enfin l'accélération (XVIII ${ }^{\mathrm{e}}$ et $\mathrm{XIX}^{\mathrm{e}}$ siècles) de l'intégration de nouvelles cultures, en dépit d'une situation d'assiégés et d'une « guerre de 100 ans » contre les Peuls pour représenter au début $\mathrm{du} \mathrm{xx}^{\mathrm{e}}$ siècle une civilisation montagnarde, sans doute la plus aboutie l'une des plus abouties? d'Afrique.

Barreteau D. 1988 - Description du Mofu-Gudur langue de la famille tchadique parlée au Cameroun. Vol. II. Lexique. Paris, Orstom, $480 \mathrm{p}$.

Barreteau D. \& Le Bleis Y. 1990 - Lexique mafa, langue de la famille tchadique parlée au Cameroun. Paris, Geuthner-Orstom, $472 \mathrm{p}$.

Boisseau J. 1975 - N’kudi Maray, fête du taureau ou la célébration de la convivialité mafa, (Cameroun septentrional). [Doc. multigraph.], 108 p. 
Boisseau J. \& Soula M. 1974 - La femme dans sa communauté territoriale, clef du cosmos mafa, Cameroun septentrional. Paris, Mémoire École Pratique des Hautes Études, T3 : 535-811.

Boutrais J. 1973 - La colonisation des plaines par les montagnards au nord du Cameroun (monts Mandara). Paris, Orstom (Travaux et documents de l'Orstom ; 24), 277 p.

Boutrais J., Boulet J., Beauvilain A., Gubry P., Barreteau D., Dieu M., Breton R., Seignobos C., Pontie G., Marguerat Y., Hallaire A. \& Frechou H. 1984 - Le Nord du Cameroun, des hommes une région. Paris, Orstom, 551 p. (Mémoires ; 102).

Burckhardt J.-L. 1819 - Travels in Nubia. London, J. Murray, XCII-543 p.

Chastanet M., Fauvelle-Aymar F.X. \& Juhe-Beaulaton D. (Ed.) 2002 - Cuisine et société en Afrique : histoire, saveurs, savoir-faire. Paris, Karthala, $291 \mathrm{p}$.

Chevalier A. \& Perrot E. 1905 - Les Coleus à tubercules alimentaires. In Les végétaux utiles de l'Afrique tropicale française Vol. 1, fasc. 1. Paris, Dépôt des publications : 100-160.

Chevalier A. 1936 - Contribution à l'étude de quelques espèces africaines de genre

Dioscorea. Bulletin du Muséum national d'histoire naturelle, $2^{\text {ème }}$ série 8 (6) : 520-551.

Chevalier A. 1947 - Les jujubiers ou Ziziphus de l'Ancien monde et l'utilisation de leurs fruits. Revue Internationale de Botanique appliquée et d'agriculture tropicale 27 (301/2) :

470-483.

Chevalier A. 1949a - À quelle époque a pris naissance la protoculture au Sahara ? R.B.A. Revue de Botanique Appliquée 321-322 : 418-419.

Chevalier A. 1949b - Sur un igname sauvage de l'ouest africain à tubercules comestibles ( Dioscorea hastifolia Pax, D. lecardii De Wild.). Revue de Botanique Appliquée 325-326 : 609-612. Connah G. 1985 - Agricultural intensification and sedentism in the Firki of N.E. Nigeria. In Farrington I.S. (Ed.) Prehistoric Intensive Agriculture in the Tropics. Part. II, Bar International Series $232: 765-785$.

David N. 1976 - History of crops and peoples in North Cameroon to A.D. 1900. In Harlan J.R., De Wet J.M.J. \& Stemler A.B.L. (Ed.) Origins of African plant domestication : 223-267.

Delneuf M. \& Medus J. 1997 - Comparaison de deux environnements anthropisés de la période protohistorique du Nord-Cameroun. In Barreteau D., Dognin D. \& von Graffenried C. L'Homme et le milieu végétal dans le bassin du lac Tchad. Paris, Orstom (Colloques et Séminaires) : 145-170.

Delneuf M. \& Otto Th. 1995 - L'environnement et les usages alimentaires en vigueur à l'époque protohistorique dans l'extrême nord du Cameroun. In Marliac A. (Ed.) Milieux, sociétés et archéologues. Paris, Karthala : 211-226.

De Wet J.M.J. \& Harlan J.R. 1971 - The origin and domestication of Sorghum bicolor. Economic Botany 25 : 128-135.

Dounias E. 1988 - Contribution à l'étude ethnoécologique et alimentaire des Koma Gimbé - Monts Alantika, Nord Cameroun. Mémoire de fin d'études. Le Havre, Istom, 240 p.

Dumont R., Hamon P. \& Seignobos C. 1994 - Les ignames au Cameroun. Montpellier, Cirad, 79 p. (Repères, Cultures annuelles).

Dury S. 1991 - Approche ethnobotanique des Ficus au nord du Cameroun. Mémoire de l'Ensam, Montpellier, UNESCO-MAB, $53 \mathrm{p}$.

Eckebil J.-P. 1970 - L'amélioration des céréales au Cameroun. African soils/Sols africains XV (1.2.3) : 21-34.

Froment A., Garine I. de, Binam Bikoi Ch. \& Loung J.-F. (Ed.) 1996 - Bien manger et bien vivre. Anthropologie alimentaire et développement en Afrique intertropicale : du biologique au social. Paris, Orstom, Paris, L'Harmattan, 516 p. 
Garine E. 2002 - Les céréales comme aliment de base des agriculteurs Duupa du NordCameroun. In Chastanet M., Fauvelle-Aymar F.-X. \& Juhé-Beaulaton D. (Ed.) Cuisine et société en Afrique, histoire, saveurs, savoir-faire. Paris, Karthala : 243-263.

Garine E., Moussa A., Raimond C., Dounias E. \& Kokou K. 2005 - Usages alimentaires du parc arboré sélectionné (Duupa, massif de Poli, Nord-Cameroun). In Raimond C., Garine E. \& Langlois O. (Ed.) Ressources vivrières et choix alimentaires dans le bassin du lac Tchad. Paris, IRD, Paris, CNRS Prodig (Colloques et séminaires) : 63-86.

Garine I de 1988 - Le sucre et le sel. JATBA 35 : 5-14.

Gauthier J.-G. 1969 - Les Fali Hou et Tsala, montagnards du Nord-Cameroun (vie matérielle, sociale et éléments culturels). Oosterhout, Pays-Bas, Anthropological publications, $272 \mathrm{p}$.

Hallaire A. 1988 - Systèmes agraires et histoire dans les monts Mandara. In Barreteau D. \& Tourneux H. (Ed.) Le Milieu et les hommes, recherches comparatives et historiques dans le bassin du lac Tchad. Paris, Orstom : 215-220.

Hallaire A. 1991 - Paysans montagnards du Nord-Cameroun, les monts Mandara. Paris, Orstom, 253 p.

Jaouen R. 1995 - L'Eucharistie du mil (langages d'un peuple, expressions de la foi). Paris, Karthala, 286 p.

Juillerat B. 1971 - Les bases de l'organisation sociale chez les Mouktélé (Nord-Cameroun). Paris, Institut d'Ethnologie, 271 p. (Mém. Inst. Ethn. ; 8).

Langlois O. 1995 - Histoire du peuplement post-néolithique du Diamaré (Cameroun septentrional) . Thèse de Doctorat, Université de Paris 1,570 p.

Langlois 0. 2005 - Aliments solides, aliments liquides. Un regard ethno-archéologique sur la poterie ancienne du Diamaré (Nord-Cameroun). In Raimond C., Garine E. \& Langlois O. (Ed.) Ressources vivrières et choix alimentaires dans le bassin du lac Tchad. Paris, IRD, Paris, CNRS Prodig : 349-375.

Langlois O., Seignobos C. \& Anderson P. 2013 - Vers une histoire du « sel de potasse » dans le nord du Cameroun : observations préliminaires. In Anderson P.-C., Cheval C. \& Durand A. (Ed.) An interdisciplinary focus on plant-working Tools. XXXIIIe Rencontres internationales d'archéologie et d'histoire d'Antibes. Antibes, APDCA : 243-259.

Le Bourgeois T. \& Seignobos C. 1995 - Végétations anthropophiles des villages de pasteurs et d'agriculteurs (région du Diamaré, Nord-Cameroun). JATBA N ${ }^{\text {elle }}$ Série, 37 (2) : 93-113.

Lembezat B. 1952 - Mukulehe, un clan montagnard du Nord-Cameroun. Paris, Berger-Levrault, $228 \mathrm{p}$.

Lembezat B. 1961 - Les populations païennes du Nord-Cameroun et de l'Adamaoua. Paris, PUF/ IIF, 252 p.

Léon l'Africain (Hassan b. Muhammad al-Fasi, dit Jean) 1956 - Description de l'Afrique. Trad. de A. Epaulard. Paris, Maisonneuve, 2 vol., 629 p.

Letouzey R. 1968 - Étude phytogéographique du Cameroun. Paris, P. Le Chevalier, 513 p. (+ cartes). (Encyclopédie biologique LXIX).

Magnavita C., Kahlheber S. \& Eichhorn B. 2004 - The rise of organisational complexity in mid-first millennium BC Chad Basin. Antiquity 78 (301). [En ligne : http://antiquity.ac.uk/ projgall/magnavita/index.html].

Maley J. 1981 - Études palynologiques dans le bassin du lac Tchad et paléoclimatologie de l'Afrique nord tropicale de 30000 ans à l'époque actuelle. Paris, Orstom, 538 p. (Travaux et Documents ; 129).

Malzy P. 1954 - Quelques plantes du Nord Cameroun et leurs utilisations. JATBA 1 : 5-6. Marliac A. 1995 - Esquisse géoarchéologique de l'évolution des sociétés pendant les deux derniers millénaires au Diamaré (Cameroun septentrional) : les données disponibles et 
leur intégration. In Marliac A. (Ed.) Milieux, sociétés et archéologie. Paris, Orstom, Paris, Karthala : 197-209.

Martin J.Y. 1970 - Les Matakam du Cameroun. Essai sur la dynamique d'une société préindustrielle. Paris, Orstom, 215 p. (Mémoires ; 41).

Miège J. 1988 - La régression des cultures vivrières traditionnelles et leur sauvegarde. Acta africana XXVI (2) : 117-132.

Miège J. \& Moncousin C. 1989 - Deux espèces à tubercules comestibles menacées de disparition : Solenostemon rotundifolius et Plectranthus esculentus (Lamiacées). Possibilité de leur conservation par micropropagation. Bull. Soc. Bot. Fr. 136 : 185-193.

Muller J.-C. 2005 - Quelques vérités sur les Dii, prétendu « peuple de l'igname » (NordCameroun). In Raimond C., Garine E. \& Langlois O. (Ed.) Ressources vivrières et choix alimentaires dans le bassin du lac Tchad. Paris, IRD, Paris, CNRS Prodig : 169-192.

Muller-Kosack G. 1989 - Problèmes de l'interprétation des données ethnographiques sur l'origine de quelques éléments de la civilisation mafa. Séminaire Mega-Tchad, Datatation et Chronologie. Bondy, Orstom, 11-12 sept. 1989, 13 p.

Muller-Kosack G. 2003 - The Way of the Beer. Ritual re-enactment of history among the Mafa, terrace farmers of the Mandara Mountains (North Cameroon). London, Mandaras publishing, $408 \mathrm{p}$.

Otto Th. W. 1993 - Phyto-archéologie de sites archéologiques de l'âge du fer au Diamaré, nord du Cameroun : le site de Salak. Thèse de doctorat, Université Montpellier II, 187 p. (+ annexes).

Pasquet R. \& Fotso M. 1991 - Les légumineuses alimentaires du Cameroun, premiers résultats. In Boutrais J. Du politique à l'économique, études historiques dans le bassin du lac Tchad. Paris, Orstom : 317-360.

Pasquet R. \& Fotso M. 2000 - Une légumineuse alimentaire, le niébé. In Seignobos C. \& Iyebi-Mandjek O. (Ed.) Atlas de la Province Extrême-Nord, Cameroun. Paris, Ird - Minrest : 88-90.

Pélissier P. 1995 - Campagnes africaines en devenir. Paris, Arguments, 318 p.

Portères R. 1950 - Vieilles agricultures de l'Afrique intertropicale L'Agronomie Tropicale 5 : 489-507.

Portères R. 1962 - Berceaux agricoles primaires sur le continent africain. J. of African History $3:$ 195-210.

Schnell R. 1957 - Plantes alimentaires et vie agricole de l'Afrique noire. Essai de Phytogéographie alimentaire. Paris, Larose, $223 \mathrm{p}$.

Seignobos C., 1982 - Matières grasses, parcs et civilisations agraires (Tchad et Nord-

Cameroun). Cahiers d'Outre-Mer 139 : 229-269.

Seignobos C. 1984 - Instruments aratoires du Tchad méridional et du Nord-Cameroun. In Seignobos C. \& Peltre-Wurtz J. (Ed.) Instruments aratoires en Afrique Noire, la fonction et le signe. Paris, Orstom, sér. Sci. Hum., 20 (3-4) : 537-573.

Seignobos C. 1988 - Le sommet du mont Ziver : un agrosystème montagnard relique. In L'homme et la montagne tropicale. Bordeaux, Sepanrit : 123-134.

Seignobos C. 1989a - Du bon usage des « mythes » par le géographe. In Tropiques, lieux et liens, Florilège offert à P. Pélissier et G. Sautter. Paris, Orstom : 117-125.

Seignobos C. $1989 \mathrm{~b}$ - Les parades à la razzia dans la zone soudanienne au xixe siècle : la domestication de la cueillette. In Eldin M. \& Milleville P. (Ed.) Le risque en agriculture. Paris, Orstom (À travers champs) : 355-373.

Seignobos C. 1992 - L'igname dans les monts Mandara. In Actes du Colloque en hommage à J. Miège, Genève novembre 1992. Genève Afrique 30 (1) : 77-96. 
Seignobos C. 1993 - L'évolution des parcs arborés des monts Mandara (Nord-Cameroun). In Symposium on agroforestery parklands, Ouagadougou, 24-27 octobre 1993, 18 p. Seignobos C. 1997a - Antiaris africana, arbre relictuel de l'extrêmité septentrionale des monts Mandara. In Barreteau D., Dognin D. \& Graffenried C. von (Ed.) L'Homme et le milieu végétal dans le bassin du lac Tchad. Paris, Orstom (Colloques et Séminaires) : 327-332.

Seignobos C. 1997b - Les arbres substituts du mort et doubles du vivant. In Barreteau D., Dognin D. \& Von Graffenried C. (Ed.) L'Homme et le milieu végétal dans le bassin du lac Tchad. Paris, Orstom (Colloques et Séminaires) : 28-34.

Seignobos C. 1998 - Les Dowayo et leurs taurins. In Seignobos Ch. \& Thys E. (Ed.). Des taurins et des hommes, Cameroun, Nigeria. Orstom (Latitudes 23) : 61-121.

Seignobos C. 1998 - Évolution d'un agrosystème à ignames, l'exemple des Dourou du Nord-Cameroun. In Actes du séminaire international : l'igname, plante séculaire et culture d'avenir, Montpellier 3-6 juin 1997. Cirad-Inra-Orstom-Coraf : 51-57.

Seignobos C. 1999 - Nomenclature commentée des instruments aratoires du Cameroun. In Marzouk J., Seignobos C. \& Sigaut F. (Ed.) Outils aratoires en Afrique. Innovations, normes et traces. Paris, Karthala, Paris, Ird : 269-310.

Seignobos C. 2002 - La lente disparition de l'éleusine dans le bassin du lac Tchad, d'une nourriture de base au rituel et à la pharmacopée. In Chastanet M., Fauvelle-Aymar F.-X. \& Juhé-Beaulaton D. (Ed.) Cuisine et société en Afrique, histoire, saveurs, savoir-faire. Paris, Karthala : 103-115.

Seignobos C. 2008 - Chèvre animal de la terre, mouton animal de l'eau (Nord-Cameroun). Journal des Africanistes 78 (1-2) : 158-182.

Seignobos C. 2009 - Migrations anciennes dans le bassin du lac Tchad, temps et codes. In Tourneux H. \& Woïn N. (Ed.) Migrations et mobilité dans le bassin du lac Tchad. Paris, IRD : 135-162. (Colloques et séminaires).

Seignobos C., Deguine J.Ph. \& Aberlenc H.P. 1996 - Les Mofu et leurs insectes. Journal d'Agr. Trad. et de Bota. Appl. 38 (2) : 125-187.

Seignobos C. \& Iyebi-Mandjek O. (Ed.) 2000 - Atlas de la Province Extrême-Nord, Cameroun. Paris, Ird-Minrest-Inc, $172 \mathrm{p}+\mathrm{CD}$.

Notice et carte (1/650 000), Parcs et végétations anthropiques : 38-43.

Notice et cartes (1/1000 000), Sorghos et civilisations agraires : 82-87.

Notice et carte $(1 / 650000)$, Alimentation de famine, répartition et stratégies

d'utilisation : 111-114.

Seignobos C. \& Schwendiman J. 1991 - Les cotonniers traditionnels du Cameroun. Coton et fibres tropicales 36 (4) : 309-322.

Seignobos C. \& Tchotsoua M. 2012 - Création de champs cultivés en terrasses dans les monts Mandara et réhabilitation des vertisols dans la plaine du Diamaré (Nord du Cameroun). In Roose E., Duchaufour H. \& De Noni G. (Ed.) Lutte antiérosive, réhabilitation des sols tropicaux. Paris, Ird (Colloques et séminaires), CDrom.

Seignobos C. \& Thys E. 1998 - Des taurins et des hommes, Cameroun, Nigeria. Paris, Orstom, 399 p. (Latitudes ; 23).

Tourneux H. 2005 - Les préparations culinaires chez les Peuls du Diamaré (Cameroun). In Raymond C., Garine E. \& Langlois O. (Ed.) Ressources vivrières et choix alimentaires dans le bassin du lac Tchad. Paris, Ird/CNRSProdig : 289-318.

Tourneux H. \& Seignobos C. 1996 - Origine et structure du lexique botanique peul du Diamaré (Cameroun). In Barreteau D., Dognin D. \& Graffenried C. von. (Ed.) L'Homme et le milieu végétal dans le bassin du lac Tchad. Paris, Orstom : 195-216. (Colloques et Séminaires). 
Tourte R. 2005 - Aux sources de l'agriculture africaine : de la préhistoire au Moyen Age, Vol 1. Histoire de la recherche agricole en Afrique tropicale francophone. FAO, $132 \mathrm{p}$.

Vincent J.-F. 1991 - Princes montagnards du Nord-Cameroun. Paris, L'Harmattan, 2 tomes, $774 \mathrm{p}$.

\section{NOTES}

1. Le champ de case représente souvent le tiers d'une exploitation montagnarde qui couvre entre 75 et 85 ares en moyenne par actif dans les années 1970 (Hallaire 1991).

2. La graphie retenue dans ce texte prend en compte les habitudes des écrits à propos du nord du Cameroun. Les noms d'ethnies s'orthographient de façon quasi phonétique : les Mofu Gudur par exemple, alors que le toponyme correspondant sera généralement conforme à la graphie des cartes : le village de Goudour.

3. «Culture de base » / « aliment de base » peuvent être compris comme «fournissant la quasi totalité de la ration énergétique ", accompagnés par des "aliments de compléments " de ladite ration qui contribuent aux qualités gustatives, avec enfin des «aliments d'appoint » pour faire face aux disettes (Schnell 1957 : 19). Nous préférons l'acception de la culture exigeant le plus d'efforts et de soins de la famille et qui produit l'aliment constituant le plat principal des repas. Le groupe lui manifestant le plus d'affect, il se trouve le mieux à même de servir la complexité des pratiques sociales (Garine $2002: 243$ ).

4. R. Jaouen (1995). Dans le nord du Cameroun on a longtemps parlé de «petit mil » (Pennisetum glaucum) et de "gros mil» (Sorghum caudatum ou durra-caudatum). On mange alors la « boule de mil », celle de « mil rouge », de « mil jaune »...

5. Le nom de «boule» vient de la forme hémisphérique que prend la pâte de sorgho plus ou moins ferme lorsqu'on la moule dans une calebasse huilée - afin d'éviter qu'elle accroche - et qu'on la sert aux convives démoulée sur un plat.

6. Les sociétés montagnardes ont cherché à développer des ensilages performants. Elles protègent leurs stocks de grains grâce à la structure de leurs silos, à la différence des ethnies de plaines, toujours à la recherche d'insectifuges efficaces. Les montagnards septentrionaux, à l'exception des Mafa, disposent de silos cyclopes avec une ouverture supérieure qui donne accès par un sas au compartiment principal du silo. Ils ont cherché à favoriser un écran protecteur des grains en surface qui condamne une petite couche de mil parasité. Sortes de ravageurs positifs, les tol ma daw des Mofu, chenilles du mil, Corcyra cephalonica et Sitotroga cereallella, vont secréter une soie collante qui agrège les grains entre eux et à la paroi. Il se formera un opercule hermétiquement clos sous lequel l'air devenu confiné protège le mil. On scelle enfin l'ouverture avec une poterie spéciale. Pour les montagnards méridionaux (Bana, Jimi, Daba), le goulot du "grenier-bouteille", après l'introduction d'une ou deux cuvettes d'eau, est fermé hermétiquement par un épais bouchon de bouillie d'éleusine. Il se crée une amorce de germination du mil stocké puis une ambiance anaérobie qui détruisent les charançons et autres ravageurs des greniers. Les récoltes peuvent se conserver ainsi plusieurs années d'affilée.

7. Dans les monts Mandara, « massif » renvoie à la fois au relief et à l'entité politico-religieuse qui l'habite.

8. Le maïs venu d'Égypte a connu une diffusion régionale à partir du Bornou. Ce maïs corné des Caraïbes possède une canne courte et des grains durs très colorés, orange, rouge et noir. Les 
informateurs affirment en déterminer deux écotypes d'après leur provenance, le plus ancien venu depuis la voie caravanière de l'ouest des Mandara, du Bornou, a transité par la chefferie de Soukour, d'où son nom : daw sagwan, et l'autre originaire de l'est, appelé malagway, toujours en Mofu Gudur.

9. La soudure peut se prolonger après les récoltes car il est difficile de consommer le sorgho nouveau directement en boule et encore moins le petit mil. Il est nécessaire d'attendre quelques mois et ce pour des raisons techniques.

10. Nous n'avons pas voulu, dans ce travail, entrer dans la description précise des préparations culinaires. Toutefois, les «farines à boire» correspondent à des bouillies très légères effectivement bues et non à celles semi fluides consommées à la cuillère, qui voisinent avec des bouillies plus compactes.

11. Les montagnards, surtout ceux des monts Mandara septentrionaux, sont de piètres apiculteurs. À la différence des abeilles, les apoïdes (mavava en mofu), Xylocopes et Trigones, improprement désignées comme mélipones, sont très nombreuses sur les massifs, surtout lors de la floraison des mils et sorghos. Leur miel, qui porte un nom différent de celui des abeilles, fait quand même l'objet d'un ramassage assidu même si ces collectes restent souvent dérisoires.

12. Bilbil vient de l'arabe soudanais belbel et même om belbel, = « la mère du rossignol ", l'ivrogne étant porté sur le chant. On relève cette étymologie populaire pour la bière de sorgho (dhourra) dans la relation de voyage en Nubie de J.-L. Burckhardt (1819: 218). La description de la boisson reprend les caractères de l'actuel bilbil. Passés du Soudan au Tchad, les groupes sara s'approprieront le terme comme la recette. Celle-ci se serait diffusée chez leurs voisins jusqu'aux Mandara (?). Toutefois la fortune de «bilbil» via les cabarets urbains et les communautés d'anciens combattants aurait été plus tardive.

13. Après un conflit entre deux massifs (Ziver et Vouzad) en 1961-1962, un quartier de Ziver a été déporté par l'administration entre Mouhour et Mokolo; "Ziver plaine » s'est couvert de terrasses en quelques années (Boutrais 1973).

14. Dans les monts Mandara, les mouvements de populations n'intéressent toujours que de modestes groupes familiaux (Juillerat 1971 : 55, Vincent $1991: 751 \ldots$...).

15. La station IRAT (Institut de recherche en agronomie tropicale) de Guétalé a dû arrêter en 1968 la sélection de ces sorghos (cerge en peul) qu'elle avait entreprise car les essais en plaine démontraient l'inadaptation totale de ces écotypes (Eckebil 1970 : 27).

16. Nous avons fait l'inventaire des sorghos dans le cadre d'un projet de l'Orstom, « Diffusion des plantes cultivées ", 1983-1984, complété avec le montage (1989-1991) de l'Atlas de la province Extrême-Nord Cameroun. P. Sapin, ingénieur généticien du Cirad a assuré l'essentiel des déterminations. Parmi le matériel récolté, les zlaraway, qui présentent quelques apparentements avec un groupe de sorghos du Nigeria dits short Kaura. Certains zlaraway sont très répandus, d'autres semblent n'appartenir qu'à un groupe.

17. J.-G. Gauthier (1969 : 53) signale un mil « à l'ombre », titu kusku, chez les Fali de Ngoutchoumi. On trouve chez les Mofu Zidim (daw mejet) et chez les Budum (daw meezed) un sorgho difficile à identifier (guinea-caudatum), tardif (5 mois), à panicule longue, épillets dégagés, grain bleuté, ou encore chez les Hina (ndri kesheng), un caudatum à panicule serrée, grain mauve/gris pâle et glume noire luisante...

18. Les mils pénicillaires présentent le plus souvent des cultivars aristés comme chez les Njegn et les Gude.

19. Ce ne sont pas les seuls à brandir un "plus civilisateur ", d'autres se mettent derrière de nouvelles cultures comme l'arachide. À Sir, chez les Kapsiki, le clan des chefs (ka mazə) actuel a obtenu le pouvoir auprès des autochtones, les Ka Bitagonje, en troquant l'arachide, alors inconnue en tant que matière grasse, contre les pierres de commandement.

20. Faidherbia albida s'avère absent du spectre pollinique de fouilles dans le «complexe de Mowo » avant le XvI ${ }^{\mathrm{e}}$ siècle AD (Delneuf \& Medus 1997 : 161). 
21. P. Malzy (1954) rappelle la consommation des fruits et feuilles de Celtis integrifolia et signale que les décoctions de ces mêmes feuilles, en ablution, soignent la variole. Or tout ce qui touche aux soins de la plus redoutée des épidémies, « le feu de Dieu » pour les montagnards, en réfère à des ingrédients alimentaires ou relevant de la pharmacopée les plus anciens.

22. Comme toute ancienne culture la plante se trouve aujourd'hui recyclée dans les rituels. Ses fibres servent à tresser des cordes dont on attache les animaux (chèvres surtout) promis au sacrifice. Une « corde sacrée » (teba en mafa), tressée en fibres d'Hibiscus asper (mishiya kwolokwa $d$ : oseille/tortue) intervient lors du maray pour sortir le taureau de sa claustration jusqu'à le conduire sur le lieu du sacrifice, moment fort du maray (G. Müller-Kosack 1989).

23. Gossypium hirsutum race punctatum vient de l'est, du Sénégal, alors que G. arboreum race soudanense est originaire du Soudan. L'un comme l'autre se sont diffusés dans les Mandara par l'intermédiaire de traitants bornouans et hausa. G. barbadense renvoie à une arrivée ultérieure depuis la côte (Seignobos \& Schwendiman 1991).

24. Chez les Mafa et Matal, l'arbre - une partie de branche - remplace le mort dont le corps est absent (décédé à l'étranger, au combat...). On place cette branche sur la planche-lit enveloppée de la peau de chèvre sacrifiée, puis on l'inhume. Le Vitex sur lequel a été opéré le prélèvement appartient dès lors à la famille du défunt et ne peut être abattu (chez les Matal) (Seignobos 1997 $\mathrm{B}: 24,25)$. Vitex participe aussi à certaines cérémonies clés comme le maray où l'on bourre de ses feuilles la gueule du taureau sacrifié. On peut supputer que pour revêtir le rôle de substitut végétal de l'homme, Vitex doniana a dû, depuis des temps immémoriaux, servir le montagnard dans sa commensalité au point d'en partager la consubstantialité.

25. Au moment de la pénétration européenne les Lamiaceae sont partout en grand recul, ce que signalent A. Chevalier 1905 (Tchad et Oubangui) de même que J. Miège et Ch. Moncousin 1989. La régression de ces tubercules semble moins redevable à de faibles productions ou à des difficultés de récoltes qu'à leur constante référence à des groupes reculés et minorés. Ils furent jugés tout comme eux «primitifs».

26. Les deux fers d'iler, dont un très beau en croissant, trouvés dans des tombes à Moundour sur les piémonts des Mandara, remontent à l'âge du fer moyen, soit entre le XII ${ }^{\mathrm{e}}$ et le $\mathrm{XV}^{\mathrm{e}}$ siècle (O. Langlois 1995 : 680). Si l'on s'en tient à l'extension de l'iler dans le bassin du lac Tchad, ils renvoient à une agriculture extensive sahélienne. Doit-on les relier à l'époque des petits mils dominant dans les monts Mandara?

27. Fers trouvés à Laf par O. Langlois (2005) et à Mouda par C. Seignobos (1989).

28. Le discours pro mils et sorghos et ceux dépréciatifs concernant l'igname chez les Dii alors qu'ils vivent de la commercialisation de ces tubercules (Muller 2005 : 172-173) rejoignent les mêmes comportements observés dans les monts Mandara. L'affectif et le religieux se manifestent à l'endroit des cultures des ancêtres reconnus qui les lient aux mils. Ils sont refusés aux cultures jugées antérieures appartenant à un fond devenu indifférencié, comme les ignames.

29. Gulom (Mafa), balam (Mofu Gudur), mblom (Zulgo), mbulum (Mineo), mibilim (Gemzek), oblom (Mada), mbla (Podokwo), bulumji (Fulfulde).

30. Le chien occupe la place où l'on gardera les poteries protectrices du mil (Barreteau \& le Bleis $1990: 331)$.

31. G. Müller-Kosack (2003: 104) le mentionne toujours chez les Mafa: «This is why people throw some of their food to a passing dog while they eat their daily meal, and they say to the dog " go and get me my millet!". Chez les Podokwo, de retour de chez les Gelebda voisins ou [de la plaine du nord] via Oudjila, le chien restitue, dans ses fèces ou ses vomissures, les graines de mil qu'il a ingurgitées lors de son voyage etc.

32. L'éleusine en fulfulde, appelée cargaari, du terme kanuri sarga, qui évoluera en cergeeri pour désigner les sorghos des lithosols des montagnards. Cerke désigne un écotype de sorgho particulier de la région de Goudour, qui appartient à l'ensemble zlaraway. Il semble difficile qu'il ait pu donner un terme générique pour les sorghos de montagne, ou par glissement 
homonymique. Chez les Mafa la boule est appelée mavar alors que dans d'autres ethnies, comme les Mineo, l'éleusine est dite movordah et movarda chez les Gemzek... Une étude linguistique fine serait nécessaire.

33. Le Sorghum caudatum est attesté au Nigeria ( $\mathrm{IX}^{\mathrm{e}}-\mathrm{X}^{\mathrm{e}}$ siècles) dans les fouilles d'une butte saw sur la frontière du Cameroun, près de l'El Beid (Connah 1985 : 780). Il faut attendre les fouilles de T.W. Otto (1993) pour trouver du Sorghum durra au ve ou vi et encore à Moundour et Tchoukol, toujours autour du $v^{e}$ siècle à l'âge du fer. Autant dire que nous ne savons pas grand chose.

34. Dans des établissements de plaine, comme à Zilum, au nord-ouest des Mandara, qui deviendront le Bornou, l'association Vigna unguiculata et Pennisetum glaucum présente dès le milieu du premier millénaire $(\mathrm{BC})$ un "premier» système de production entraînant d'importantes formes d'ensilage inconnues auparavant (Magnavita et al., 2004).

35. Les niébés viennent obligatoirement de l'est, des terres abyssines, les domestiqués comme les sauvages restés dans la commensalité de l'homme. Ils auraient connu une forme d'aboutissement de leur domestication dans le bassin du lac Tchad.

36. Luxereau A., Dussert Y., Abad A., Snirc A., Lakis G., Maï-Ousmane A., Lamy F., Raimond C., Garine E., et T. Robert. (ss presse) La diversité des échanges de plantes : regards interdisciplinaires. In Magrin G., Baldi S., Langlois O., Raimond C., (eds). Echanges et communications dans le bassin du lac Tchad. A paraître in Annali dell'Università degli Studi di Napoli « L'Orientale ».

37. Le fulfulde permet de former sur une même racine le nom de la plante, et ceux de sa feuille, de son fruit et éventuellement de son bois et cela bien évidemment s'il y a un intérêt particulier à le désigner. Dans le cas de Celtis integrifolia (ganki) il n'existe aucun rapport étymologique entre le nom de la plante et celui de ses produits: wanko: feuille sèche de Celtis; kolommbolu, feuille fraîche de Celtis; bib6e gande, fruits de Celtis (Tourneux \& Seignobos 1996: 196). Cette désignation différenciée de celle de l'arbre, du fruit, des feuilles de Celtis se retrouve dans bien d'autres langues. Cela pourrait rendre compte d'une utilisation ancienne et régulière des produits du micocoulier africain.

38. Le mois d'août se nomme zebak chez les Mofu.

39. D. Barreteau (1988:158) en signale un certain nombre pour les Mofu Gudur et D. Barreteau \& Y. le Bleis (1990) réservent également quelques entrées de leur dictionnaire à certaines sauces aux niébés chez les Mafa.

\section{RÉSUMÉS}

Nous avons fait le pari de remonter le temps d'une histoire du manger et du boire dans les monts Mandara. île montagnarde plantée dans le bassin tchadien, elle a enregistré les diffusions de plantes en décalage par rapport aux plaines environnantes, mais par conservatisme ses populations en ont entretenu plus longtemps la culture. Ce milieu contraint a suscité à partir de parcs arborés précisément sélectionnés des formes d'extractivisme très contrôlées.

Ces humanités montagnardes ont évolué et avec elles leurs agrosystèmes. Nous avons retenu dans ces sociétés autarciques, trois grandes «époques agraires " et partant alimentaires. La première prend l'aspect d'une horticulture de montagne avec des ignames et de petits tubercules; elle sera peu à peu gagnée par une céréaliculture d'éleusines et de mils pénicillaires pour aboutir au complexe agricole céréalier de sorghos de ces derniers siècles. Depuis «les 
commencements » un ensemble oléo-protéinagineux centré sur les niébés a favorisé ces différents modes d'agricultures montagnardes. Ces légumineuses ont soutenu la diète des populations quelles que soient les associations et les rotations culturales découlant de disciplines portées par des choix aussi sociaux qu'économiques.

Jouant sur des faisceaux d'indices nous n'avons pu envisager que de probables successions de combinaisons agraires qui attendent dès lors d'être infirmées ou confirmées par des démarches disciplinaires autorisées à marquer le temps.

Our intention in the present paper is to go back in time and lay out the history of eating and drinking in the Mandara Mountains. Located in the Chad Basin area, the Mandara Mountains often lag behind the neighbouring plains when it comes to the diffusion of plants, even though they did manage to maintain these crops over longer periods of time. Such an enclosed environment only allowed a selected vegetation to grow, from which specific and controled collecting methods have developed.

These mountain dwellers have evolved together with their agrosystems over time. This history can be divided into three major periods. The first one is characterized by a mountain horticulture with yams, small tubers, gradually replaced by cereals such as eleusines and millets (Pennisetum glaucum), and finally ending in the Sorghum complex of the last past centuries. Since the remotest times, a set of crops focused on cowpeas (Vigna unguiculata) have allowed these diverse ways of moutain farming to develop. Such leguminous plants formed the basis of the local diet, irrespective of the associations and rotations of crops stemming from social or economic considerations.

We have only been able here to point out probable successions of agricultural combinations which are now awaiting further investigations from other disciplines such as archaeology in order to be confirmed or not.

\section{INDEX}

Mots-clés : alimentation, évolution des agrosystèmes, diffusion et extinction de cultivars, ignames, éleusines, petits mils, sorghos, cucurbitacées

Index géographique : nord Cameroun

Keywords : north Cameroon, food, agrosystems, cultivars diffusion and disappearing, yams, millets, sorghums, Cucurbitaceae

\section{AUTEUR}

\section{CHRISTIAN SEIGNOBOS}

Géographe, directeur de recherche émérite IRD 